\title{
PATHOLOGY OF PREGNANCY TOXEMIAS
}

\author{
BY HARRY M. ZIMMERMAN AND JOHN P. PETERS \\ (From the Departments of Pathology and Internal Medicine, Yale University School of \\ Medicine and the New Haven Hospital, New Haven)
}

(Received for publication December 18, 1936)

In an attempt to determine the cause and nature of the toxemias of pregnancy, the records of patients who were admitted to the New Haven Hospital with the diagnosis of toxemia of pregnancy or who had renal or vascular disease that had apparently arisen during pregnancy have been reviewed. Altogether 309 of the first class and 11 of the second were found with records complete enough to warrant analysis. Of this group 53 died and 25 came to autopsy. The present paper deals with 23 of these autopsies. One of the 25 was omitted because the data of the autopsy, which was performed at another hospital, are inadequate; the second because there is some doubt about the diagnosis of toxemia. This patient had a diaphragmatic hernia which was responsible for her death and possibly for the earlier symptoms that were ascribed to toxemia.

The essential postmortem findings and clinical data are presented at the end of the article. In 10 instances, only the briefest clinical notes are given, because these cases have been reported in detail in another connection elsewhere (1). A brief tabulation of the patients appears in Table I. Thirteen died as a direct result of the toxemia, which took an eclamptic form in 6 ; the other 10 died with late sequellae of the disease, which had begun with an eclamptic attack in one.

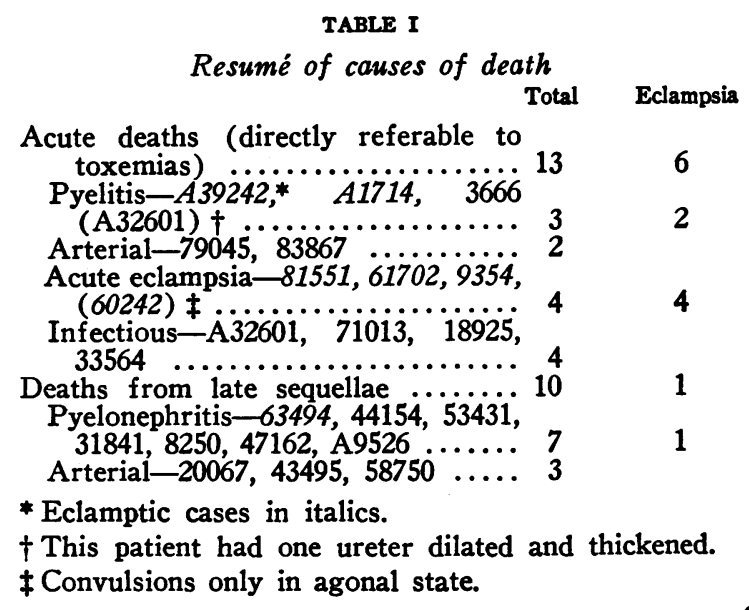

The first notable thing is the frequency with which pyelitis or its ultimate consequence, pyelonephrosis, is encountered. In this series these conditions were found in 10 (possibly 11) of the 23 subjects, 3 (possibly 4 ) with acute deaths and 7 among the remote chronic deaths. One of the latter, 63494, initially had typical eclampsia and 2 of those who died acutely. A39242 and A1714, also had eclampsia. The third, who died acutely, 3666, might also be placed in the eclamptic class, save for the absence of convulsions. Objection may be raised to the application of the terms toxemia or eclampsia to patients who have obvious pyelitis. The strongest justification for such a course lies in the fact that they received these diagnoses during life because they presented clinical signs and symptoms indistinguishable from those which characterize the toxemias. In fact, the true pathological lesions in none of these cases were surmised before autopsy. This is also true of most of the chronic cases, which were believed to have glomerular nephritis or nephrosclerosis.

If the three acute cases, A39242, A1714 and 3666 , are analyzed further, it is found that they present, in addition to pyelitis and pyelonephritis, certain more subtle pathological lesions which are quite widely accepted as characteristic of eclampsia. These deserve some description and discussion before the argument proceeds.

Degenerative changes and necrosis of the epithelial cells of the renal tubules have long been recognized as the commonest pathological lesions of the toxemias of pregnancy. By some, they have been connected more particularly with the convulsive syndromes to which the term eclampsia has been applied. The degree of degeneration of the tubular cells varies from mere cloudy swelling to a necrosis which may be so extreme and widespread that the epithelium seems to be almost as universally destroyed as it is in acute mercurial poisoning. The process is usually maximal in the convoluted tubules. Because the lesion is 
purely desquamative Volhard and Fahr (2) have identified it with nephrosis.

In addition to the tubular lesions definite changes can be discerned in the glomeruli. These have been minutely described by Bell (3), who considers them more characteristic than the tubular lesions. The lining membrane cells occasionally become swollen, sometimes necrotic-when they may be desquamated; the endothelial cells of the capillary loops more frequently are also swollen. They tend to increase in number and impart an excessive cellularity to the glomeruli. The lumina of isolated capillary loops appear to be occluded by swollen and proliferated endothelial cells. The basement membrane between the lining epithelium and capillary endothelium becomes thickened, in consequence of which the capillary loops, especially where they appear in cross section, have a staring open appearance with sharp double outlines to their walls. This change in the basement membrane is perhaps the most characteristic feature of the renal lesions in the toxemias. It may be so marked as to obliterate the capillary lumen. In addition, material resembling fibrin in its staining reactions appears in localized deposits that may be quite diffuse in certain capillary tufts. The glomeruli usually appear rather avascular, although there is distinct variability in this respect. Not rarely congested loops are seen, and extravasated blood cells may appear in the glomerular spaces. These are, however, more often found empty or contain only a little albuminous material and occasional desquamated epithelial cells. Scattered tubules, likewise, may contain masses of blood; but the great majority are filled with albumin and cellular debris. Often the narrow lumen left by the swollen epithelium appears to be entirely plugged by this debris. The striking thing about such kidneys is the absence of inflammatory reaction in the interstitial tissue and the preservation of those structures which are essential for the architecture of the organs. One derives the impression that no damage has been done which is not reversible or reparable, like the comparable injury of mercurial poisoning.

Whether the condition arises from primary vascular injury or whether it affects the renal epithelium directly, it is not easy to say. Post- mortem examination reveals no similar lesions elsewhere in the vasculature or in other organs except the liver, which will be given especial consideration later. In certain instances, to be sure, focal hemorrhages may be found in the heart, and other organs, and both edema and hemorrhages are quite regularly found in the retina. However, the possibility of generalized vascular changes cannot be summarily dismissed because it cannot be demonstrated in autopsy material. The invariable incidence of hypertension is incontrovertible clinical evidence of a generalized vascular reaction, whether this be merely a functional response or connected with anatomical changes that have thus far escaped detection.

Renal lesions are so invariably found in patients who died of acute toxemias that there can be little doubt of their significance. Moreover, the symptomatology of the toxemias resembles more than anything else the picture of acute nephritis. Edema, hypertension, albuminuria and convulsions, with or without visual disturbances, clearly spell nephritis to anyone with experience in clinical medicine. Nevertheless, great importance has been attached to certain lesions in the liver which are encountered in a portion of patients with toxemias. These lesions in their most typical form consist of hemorrhages and necrosis of the hepatic cells, especially in the periportal areas. By some, these are attributed to the presence of fibrin or hyalin thrombi in the periportal venules. It is generally admitted that these lesions are less consistently found than those of the kidney, and furthermore that the symptoms of toxemias do not resemble those of hepatic disease. Nevertheless, most extensive investigations have been carried out in an attempt to incriminate the liver. It is true that some measure of hepatic insufficiency can be demonstrated in many patients with severe toxemias and that jaundice is not uncommon in these conditions. A certain number of women, moreover, in the later stages of pregnancy or in the puerperium develop jaundice without any of the classical signs of toxemia. They are presumably suffering from destructive lesions of the liver which may be so extreme as to produce the picture of fatal acute yellow atrophy. Whether this is merely an advanced stage of the periportal necrosis of "eclampsia" cannot 
be stated with certainty. There is no physiological nor pathological evidence that hepatic destruction can give rise to hypertension. Consequently, there has been a growing tendency to relegate the liver lesions to a subordinate place in the etiology of toxemic symptoms, and to concecle the chief role to the kidney.

If it be granted that the ultimate criteria of toxemias, and especially eclampsia, are not clinical signs and symptoms, but the characteristic pathological lesions, the three acute pyelitis cases mias. Neither presented at any time symptoms or signs which could be called eclamptic. Both died from rupture of dissecting aortic aneurysms and presented vascular lesions in kidneys and other organs that conform to the description of malignant nephrosclerosis, according to Volhard and Fahr (2). Both had received a diagnosis of arterial hypertension on the basis of the symptoms and signs during their initial toxemias, the last pregnancies and the intervening periods. The blood pressure in Case 83867 was so variable and

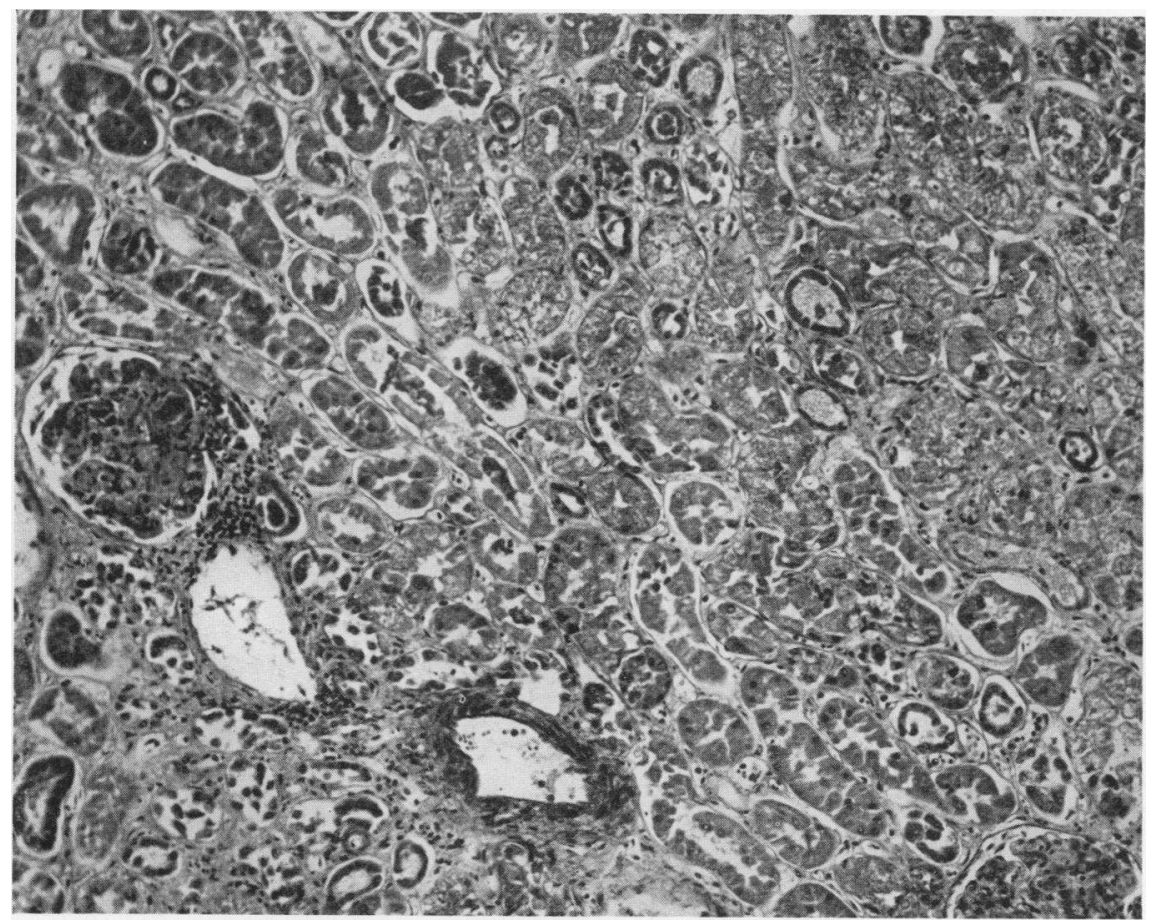

\section{Fig. 1. Case A39242. Pyelitis Early in First Pregnancy Culminating in ECLAM PSIA.}

Note extensive tubular epithelial necrosis. Hematoxylin-eosin stain; $\times 125$.

(A39242, A1714, 3656) cannot be excluded (Figures 1 to 4$)$. All exhibited typical tubular and glomerular changes, and one, at least, A39242, also had periportal necroses. To argue that the relation between pyelitis and toxemia in these cases was merely coincidental involves a dangerous preconception. It may well be that these renal and hepatic lesions represent only the pattern in which the pregnant woman reacts to a variety of insults. Some support for such an hypothesis is found in Cases 79045 and 83867. Both of these patients died during recurrent toxe- her symptoms and signs so slight that she was considered to have benign or functional nephrosclerosis. In the light of these facts the postmortem anatomical findings are surprising in the extreme. The existence of arterial disease of a malignant type is undeniable. That it antedated the final pregnancy is highly probable in view of the history and physical findings. Nevertheless, the kidneys and livers of both patients had characteristic "eclamptic" lesions. In fact Case 83867 probably presents the most extreme periportal necroses found in this series of autopsies. 


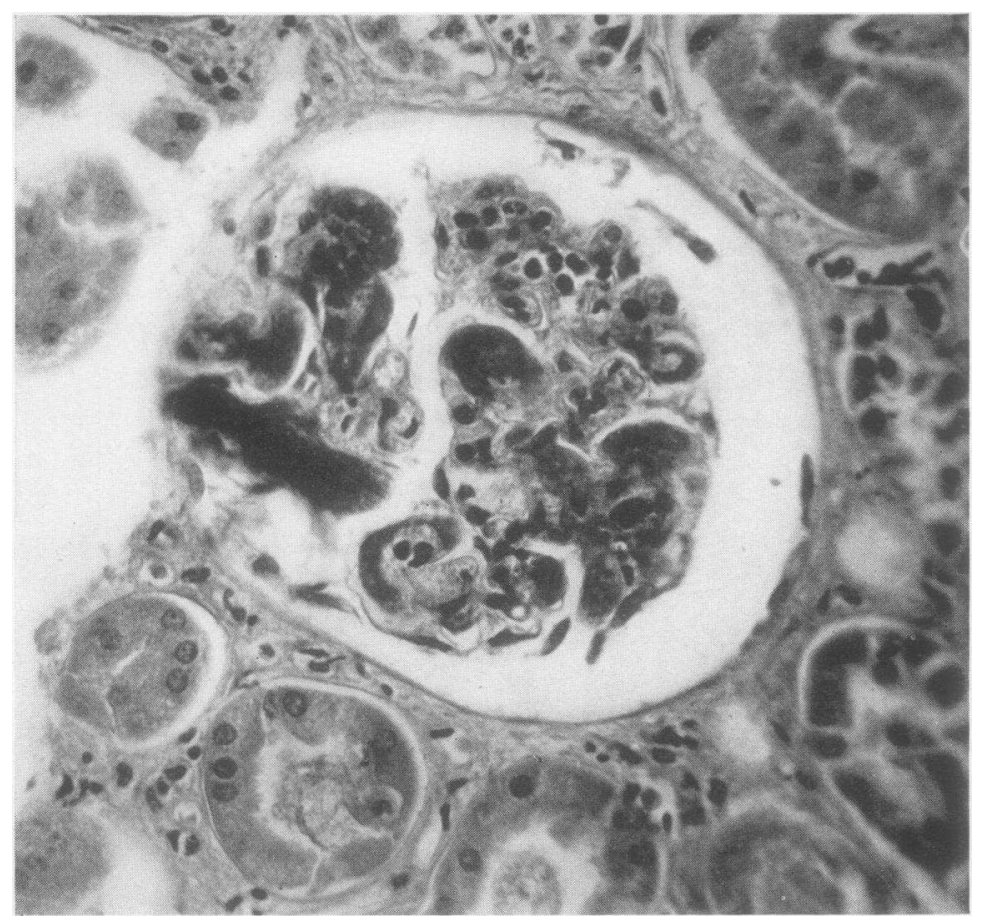

Fig. 2. Case A39242. Marked Thickening of Basement Membrane of Capillary Endothelium Resulting in Complete Occlusion of Capillary Lumina in some Glomerular Tufts.

Hematoxylin-eosin stain; $\times 250$.

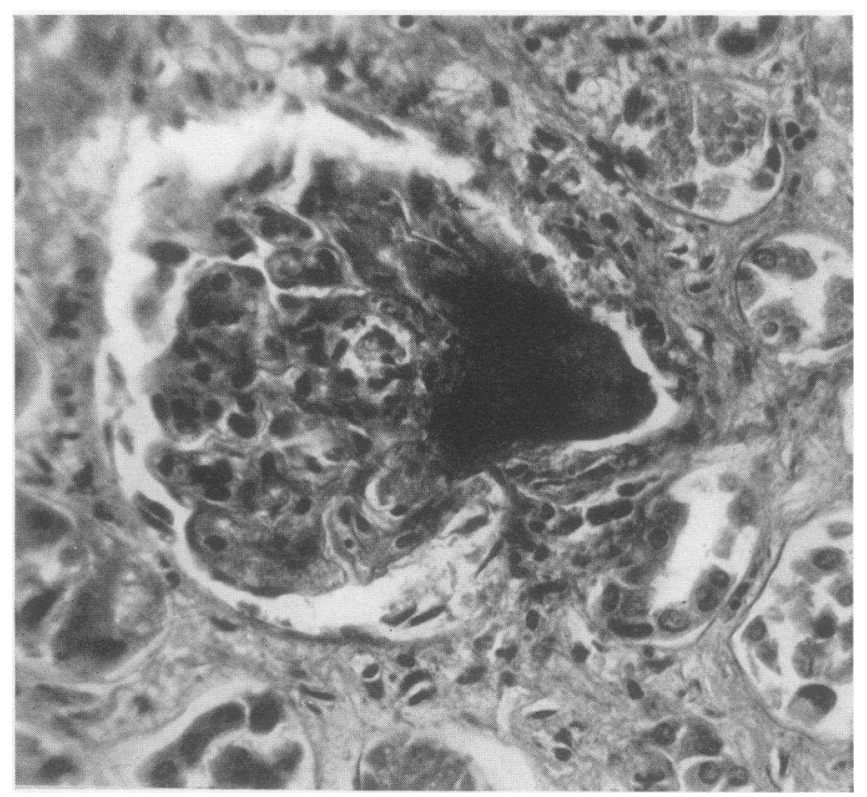

Fig. 3. Case A39242. Fibrin-Like Deposit in Glomerdlar Capillary Tufts.

Hematoxylin-eosin stain; $\times 250$. 
Three other acute cases (81551, 61702 and 9354) exhibited clinically the picture of eclampsia; but only the first 2 presented characteristic lesions at autopsy. The third, 9354, showed surprisingly little at postmortem examination. There was, to be sure, some cloudy swelling of the hepatic cells and the renal tubules and a few hemorrhages were found in the kidneys. But no anatomical justification for the patient's death was discovered. To assume that the toxemia was so fulminating that there had not been time for the processes in immediate cause of death was an acute illness which began 12 days after an apparently normal delivery and which was characterized by abdominal pain, vomiting, jaundice, coma and circulatory collapse. The whole picture suggested more than anything else a fulminating puerperal infection; but no marks of an inflammatory process were discovered at autopsy. Case A32601, after a period of edema and hypertension, succumbed to an acute bronchopneumonia. It should be remarked that the patient with pneumonia had far

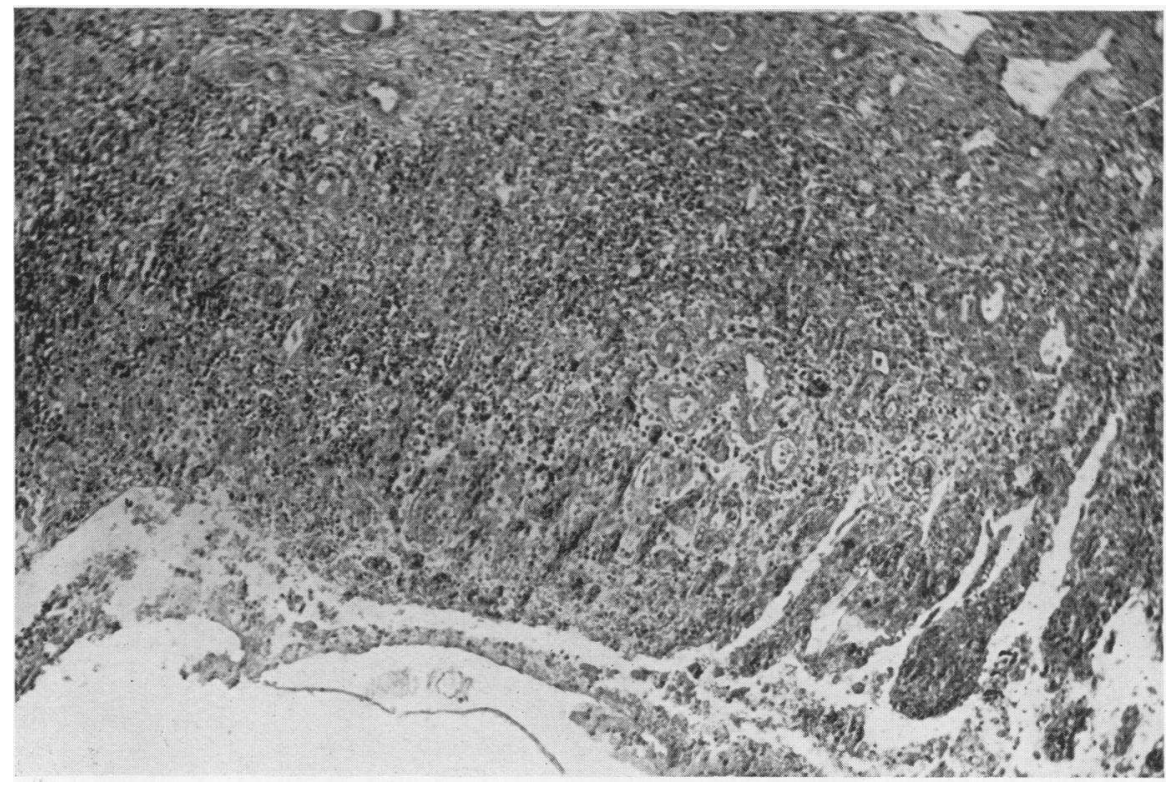

Fig. 4. Case 3666. Second Pregnancy Terminated at 8 Months for Toxemia.

Miscarriage at 5 months-edema. Chills, dyspnea, orthopnea, headache, vomiting and blurred vision in following pregnancy. Chronic and acute pyelitis, showing necrosis of pelvic mucosa, hemorrhage and cellular infiltration. Hematoxylin-eosin stain; $\times 90$.

kidneys and liver to develop completely is not consistent with the facts, since edema and urinary symptoms had preceded the acute eclamptic syndrome by some weeks. It is equally unsatisfactory to ascribe death to some overwhelming functional disturbance. Such baffling mysteries appear to confuse issues in every series of autopsies.

Tubular and hepatic necroses (Figure 5) were found at autopsy in 2 additional cases (60242 and A32601) who did not present in life the clinical syndrome of eclampsia. Case 60242 is reported to have had antecedent kidney disease, of which only slight evidence was found at autopsy. The more extensive hepatic destruction than the one who had abdominal symptoms and jaundice.

Of 6 patients, then, that died in the acute stages of toxemias with symptoms of eclampsia, only 5 had the characteristic lesions in the kidneys or liver. Three of these had, in addition, pyelitis. Typical tubular and hepatic necroses were found at autopsy in 4 other cases which did not present in their final illnesses pictures of eclampsia. Two had all the signs and symptoms of chronic arterial disease with acute exacerbations and both died from rupture of dissecting aneurysms of the aorta; one succumbed to pneumonia. This short roll offers no support to those who claim that 
eclampsia is a distinct entity, whether they choose as criteria symptom complex or autopsy findings. Certainly no correlation can be traced between ante and postmortem pictures by the use of accepted standards. By the same token conventional classifications of the toxemias are rudely shaken: Two of the patients with pyelitis and the two with arterial disease suffered from antecedent renal and vascular conditions of which evidence was found in both clinical histories and toxemia is generally applied. It would be hard to exclude her while admitting 60242, whose symptoms did not appear until some time after delivery. The latter, however, is one of those who had tubular and hepatic necroses. The autopsy findings in 71013 are quite in keeping with the clinical story. Essentially she presented an inflammatory type of renal disease with acute lesions, chiefly in the tubules, and some interstitial scarring (Figure 6) which proved that the con-

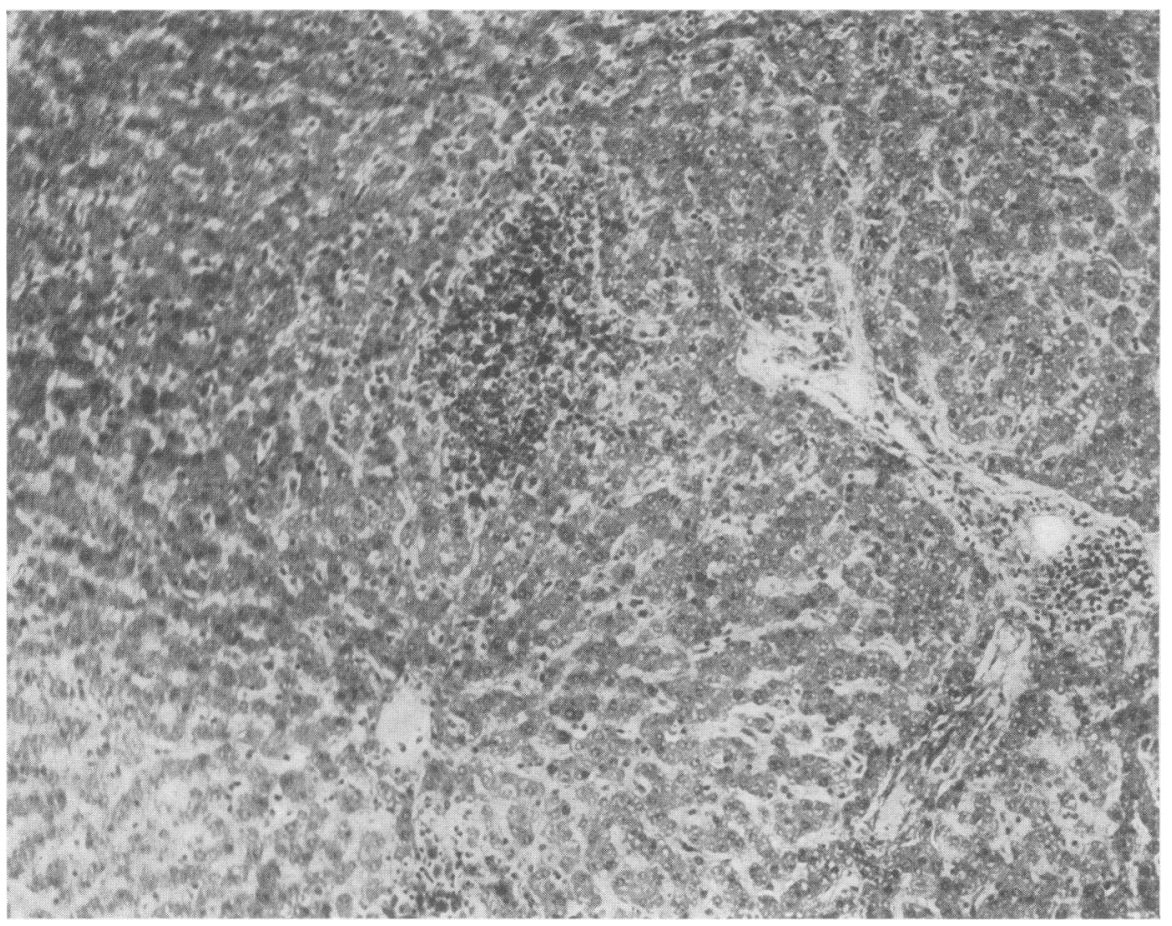

Fig. 5. Case 60242. Onset of Symptoms 12 Days after Birth of First Child.

Necrosis of liver cells and hemorrhage on periphery of liver lobule. Hematoxylineosin stain; $\times 125$.

autopsies. They should, then, have been expected to react according to the patterns described in one well-known classification by the terms, "lowreserve kidney" or " nephritic toxemia."

There remain 3 acute cases to be considered: 71013, 18924 and 33564. The first died 4 months after termination of pregnancy. It may seem hardly proper to include her among the toxemias, especially since she was not seen until shortly before death. Nevertheless, her illness seemed to develop by a continuous progression from symptoms which began during pregnancy and which resembled in all respects those to which the term dition had existed for some time, but not necessarily longer than her history would indicate. The appearance of the kidneys and the other organs suggests an infectious etiology. Unfortunately bacteriological studies were entirely inadequate.

The next case (18925) is somewhat similar. There is a story of transitory edema on 3 previous occasions. For a month before her premature delivery she had suffered from edema and for 2 weeks from headaches, dizziness and blurred vision. She presented striking hypertension, albuminuria and microscopic pyuria, hematuria and cylindruria, and some nonprotein nitrogen reten- 
tion. A diagnosis of toxemia of pregnancy was made and labor induced. After delivery she lapsed into a state of shock and subsequently developed signs of sepsis. At autopsy she proved to have a bacterial endocarditis and other evidences of infection that led at first to the impression that she had died of puerperal sepsis. The lesion on the heart valves, however, obviously antedates delivery. In the kidneys are found the typical embolic lesions of bacterial enclocarditis rarely attended by hypertension. Even if there is concomitant obstruction of the urinary tract, the blood pressure usually rises only after a long period when there has been massive destruction of the kidneys. The fact that it ultimately develops in the majority of cases proves that the potentialities of hypertension and arterial disease reside in pyelonephritis, ready to take form whenever the proper conjunction of circumstances arises. Pregnancy appears to provide the stage

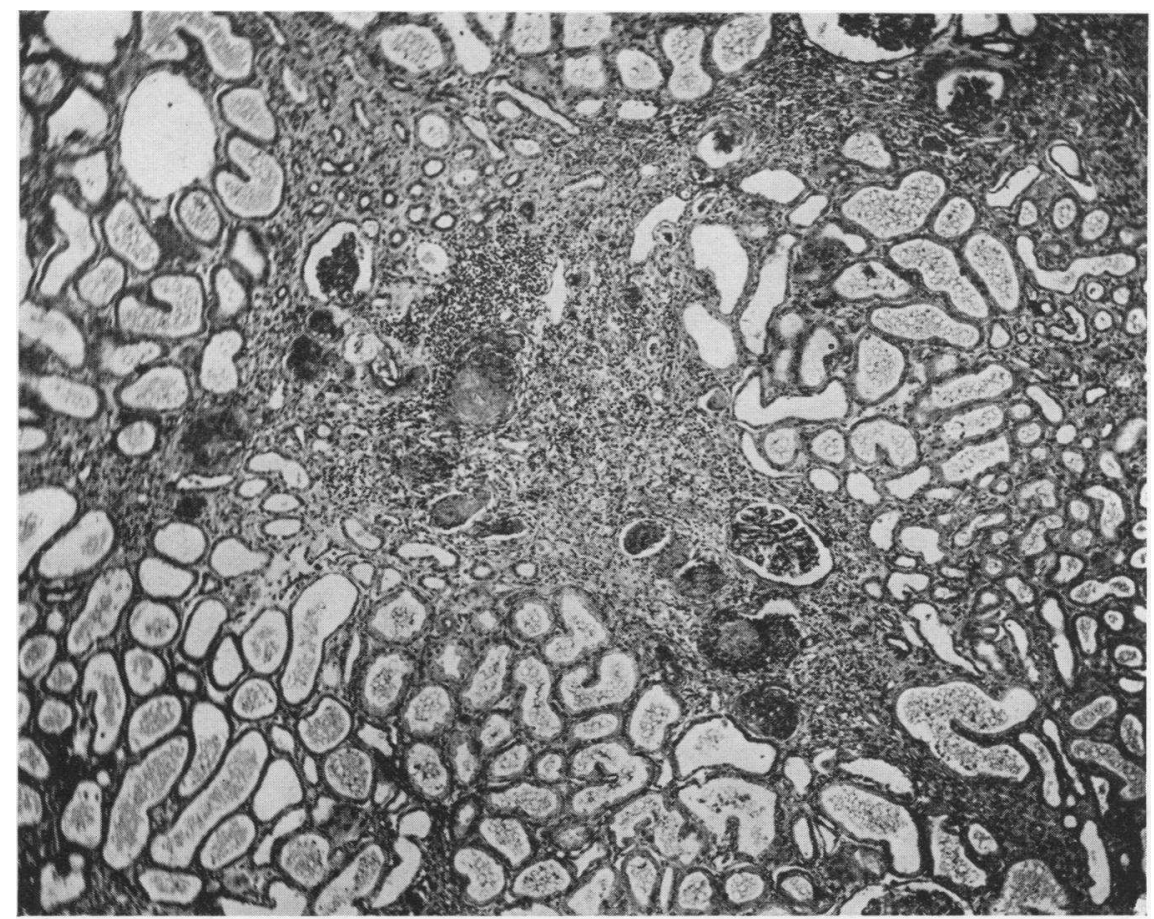

Fig. 6. Case 71013. Pregnancy Terminated becalse of Orthopaea, Dyspaea AND EDEMA OF FeET.

Increase of symptoms during next four months. Renal cortical scar infiltrated with many small round cells. In other fields (not represented in photomicrograph) many tubules found with leukocytic cellular casts. Hematoxylin-eosin stain; $X 60$.

together with an acute diffuse nephritis and extensive tubular necrosis. Since the patient must have had during her toxemia the bacterial endocarditis and the nephritis, it seems quite unnecessary to attribute the toxemic syndrome to another pathological condition.

It is unusual, to say the least, to find extreme hypertension, diffuse nephritis and such fulminating toxic manifestations in the early stage of an acute bacterial endocarditis. This may be the coloring which pregnancy gives to the picture. Acute pyelitis, also, in non-pregnant subjects is setting to elicit hypertension and other nephritic manifestations in an acute or fulminating form, usually with anatomical abnormalities that take a rather particular pattern.

The last acute case, 33564 , cannot properly be classed among the toxemias. She had chorea of major intensity with acute rheumatic endocarditis, myocarditis and nephritis. She is included in this series only because the possibility again arises that the unusual and malignant features of the cases were contributed by pregnancy.

Altogether the part which infections played in 
the etiology of these toxemias is far from negligible. Besides these last 3 cases (if 33564 is included), A32601 with pneumonia, possibly 60242 with the postpartum abdominal symptoms and jaundice, and certainly the 3 pyelitis cases, all had frank evidences of infectious disease. In addition 83867 had an active rheumatic mitral endocarditis. This accounts for 9 of the 13 patients who died acutely from toxemias. Just what rôle these infections played in the etiology of the toxemias and Tillman (4), and Mussey and Keith (5) as the result of analyses like the present one, aimed to discover the nature and pathogenicity of toxemias by comparing them with analogous medical conditions, have independently reached the conclusion that toxemias belong predominantly among the nephroscleroses, chiefly of the benign type. These conclusions are based on consideration of the symptomatology of the toxemias and their sequellae. Keith and his associates recognize al-

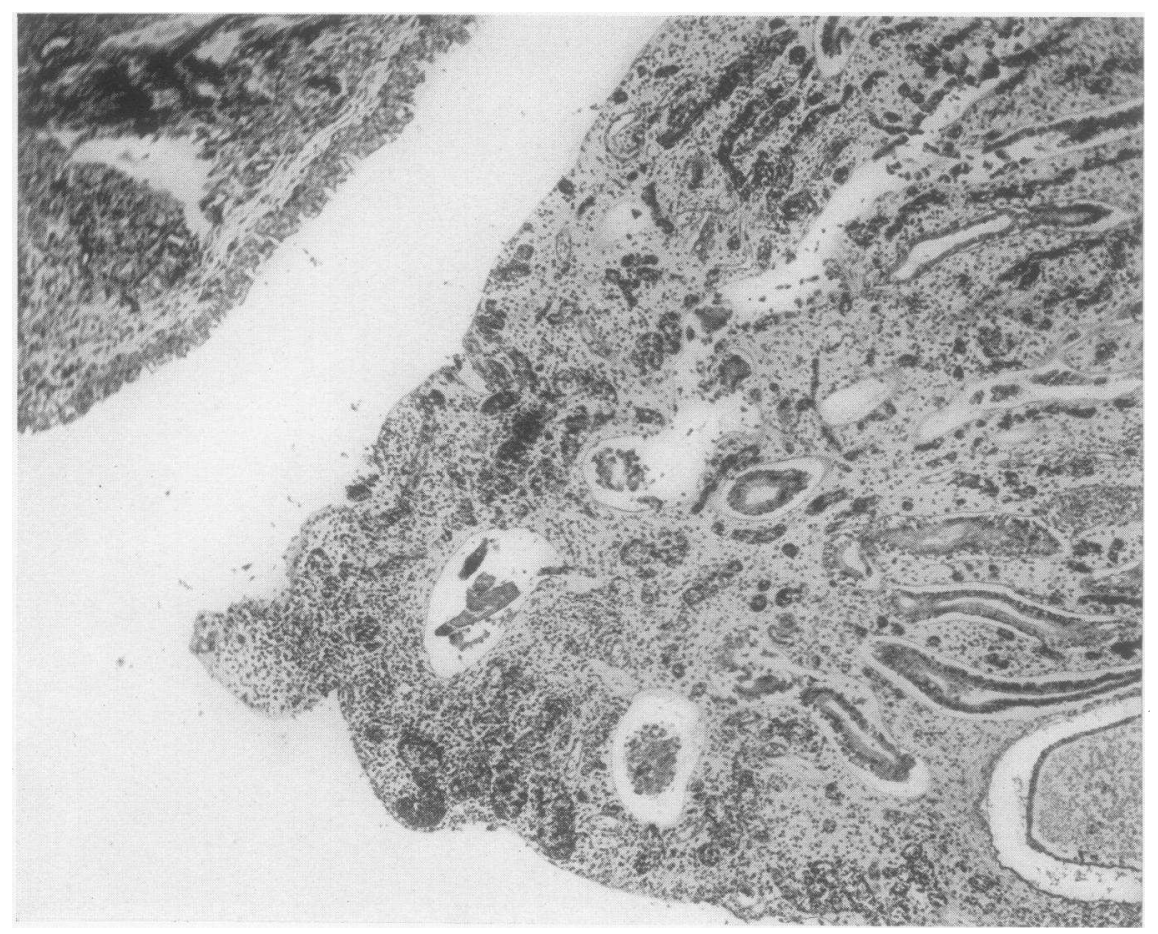

Fig. 7. Case 63494. Eclampsia im mediately after Delivery of First Child.

Febrile puerperium, associated with pyuria. Hypertension 10 weeks after delivery. Five years later advanced renal and cardiac failure. Photomicrograph showing apex of pyramid. Desquamated mucosa and infiltration of lymphocytes, plasma cells and large mononuclears. Hematoxylin-eosin stain; $\times 60$.

and how far they contributed to the fatal ending in some of the cases, it is impossible to say. It may be a little more than fortuitous that in almost every instance the infection was of the kind that in non-pregnant persons may give rise to renal and vascular disease, either because of its inherent nature or because of its anatomical position. Beyond this it seems idle to carry inference or conjecture about the acute cases.

There are certain points about the remote or chronic deaths that deserve mention. Herrick most all the types of renal and vascular disease found in the classifications of Volhard and Fahr (2), to which they adhere. In the present series, also, the chronic cases, if they are considered only from the standpoint of clinical manifestations, would almost without exception have been relegated to nephrosclerotic categories. Nevertheless 8 out of 11 proved to have secondarily contracted pyelonephritic kidneys (Figures 7 to 10). The error lies in the notorious failure to recognize that chronic pyelonephrosis manifests itself, until 
the terminal stages, chiefly in vascular phenomena. It is not improbable that similar errors of diagnosis in other series have overweighted the nephroscleroses at the expense of the pyelonephroses.

The three who did not exhibit infected pyelonephrosis were found to have arterial disease, especially in the kidneys, with the lesions to which Volhard and Fahr (2) applied the term malignant nephrosclerosis (Figures 11 and 12). It is worthy of note in passing that unless it be assumed that only findings of importance in 3 of the chronic cases (20067, 43495 and 58750), cannot, on this account, be said to constitute a clinical entity. Similar lesions were found in the renal vessels of all the patients who died of pyelonephrosis (Figure 9), and sometimes in the extrarenal arterioles as well $(44154,31841)$. They appeared even in the kidneys of the two acute pyelitic cases which had antecedent toxemias (A1714 and 3666). Presumably they originated in these cases and in

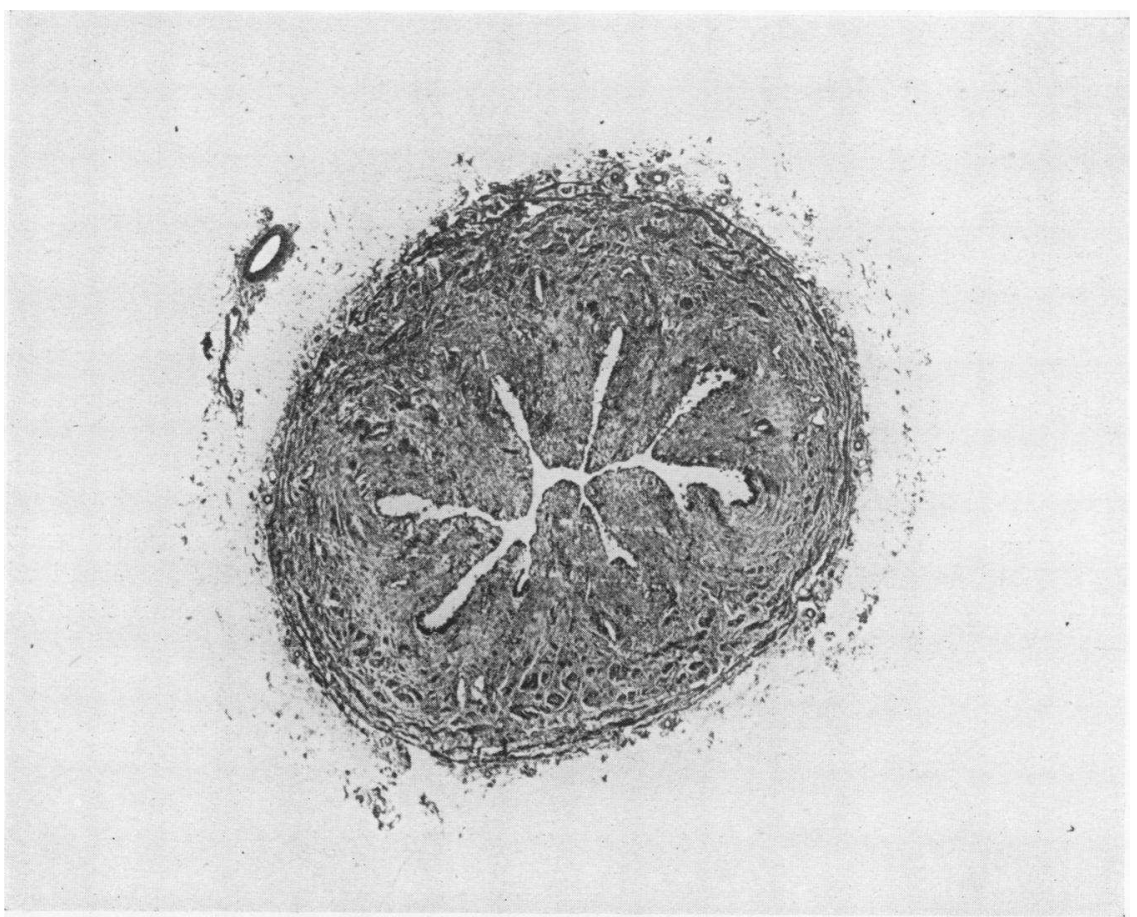

Fig. 8. Case 63494. Chronic Ureteritis Showing Marked Thickening of URETERal Wall.

Hematoxylin-eosin stain; $\times 15$.

initially the hypertension in these patients was of a different nature, the term " malignant" is somewhat inappropriate. Toxemic patients afford a peculiarly favorable opportunity for the investigation of these arterial lesions because they permit reasonably accurate estimation of the inception and duration of the disease. The stories of 79045 and 83867 in the acute series, who proved at autopsy to have malignant nephrosclerosis, indicate quite clearly that the clinical picture associated with this pathological lesion may be extremely benign for long periods.

The nephrosclerotic lesions, which were the
79045 and 83867 in the previous toxemias. This gives rise to some interesting speculation. If the only anatomical mark which stigmatizes all these patients in common during the acute stages of the disease is the desquamative process in the kidneys and the only universal residua of toxemias are the arteriolar changes of malignant nephrosclerosis, the temptation is great to infer that there is more than a casual relation between the two conditions. The unexceptional incidence of hypertension lends weight to the argument that toxemias must be associated with a diffuse arterial reaction even if no anatomical counterpart for the functional de- 


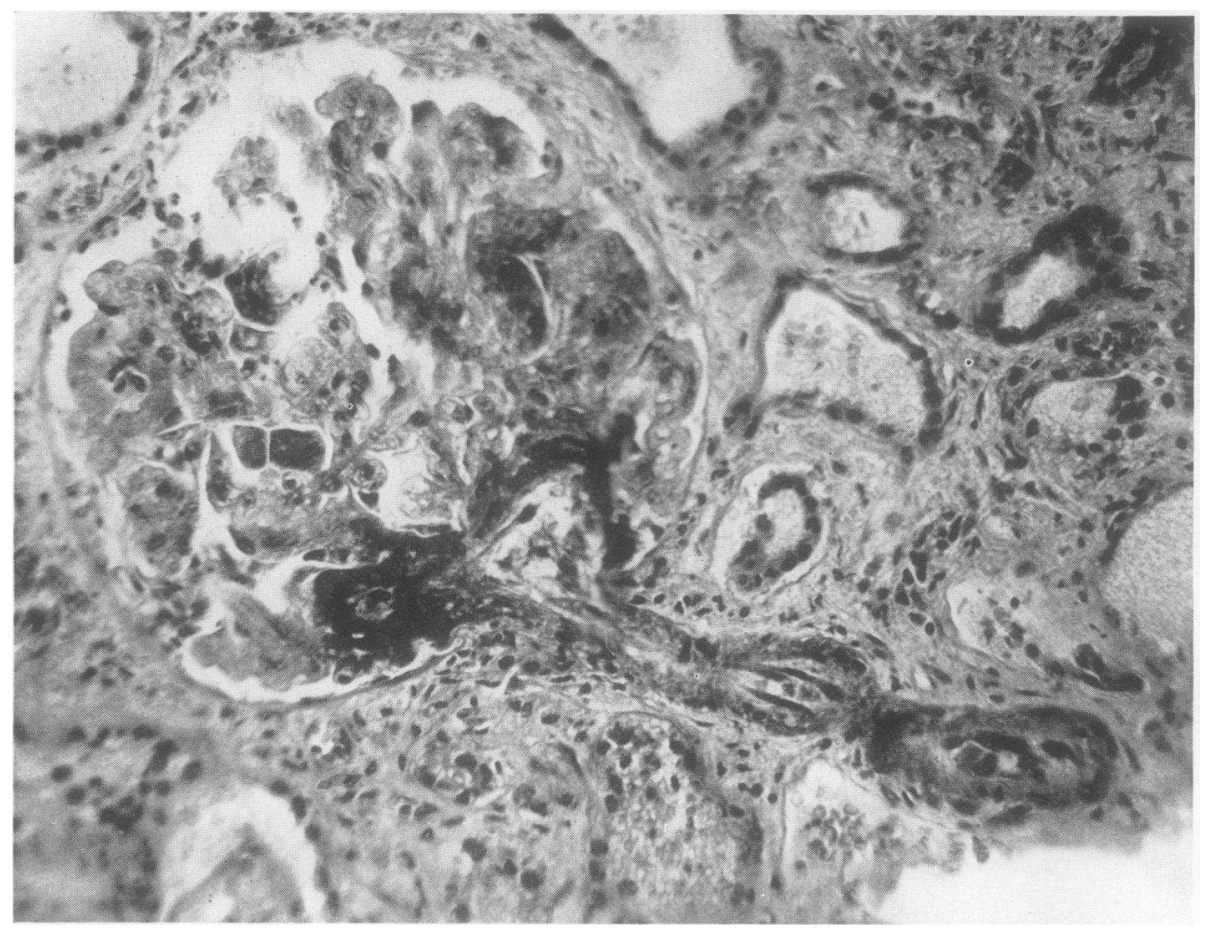

Fig. 9. Case 31841. Pyelitis in 1918, Aggravated by Pregaxancies in 1924 and 1926.

Increasing urinary symptoms, hypertension and renal and cardiac failure, ending fatally in 1932. Fibrin-like deposition in capillary loops of glomerulus associated with marked thickening of afferent arteriole (picture of "malignant nephrosclerosis"). Hematoxylin-eosin stain; $\times 200$.

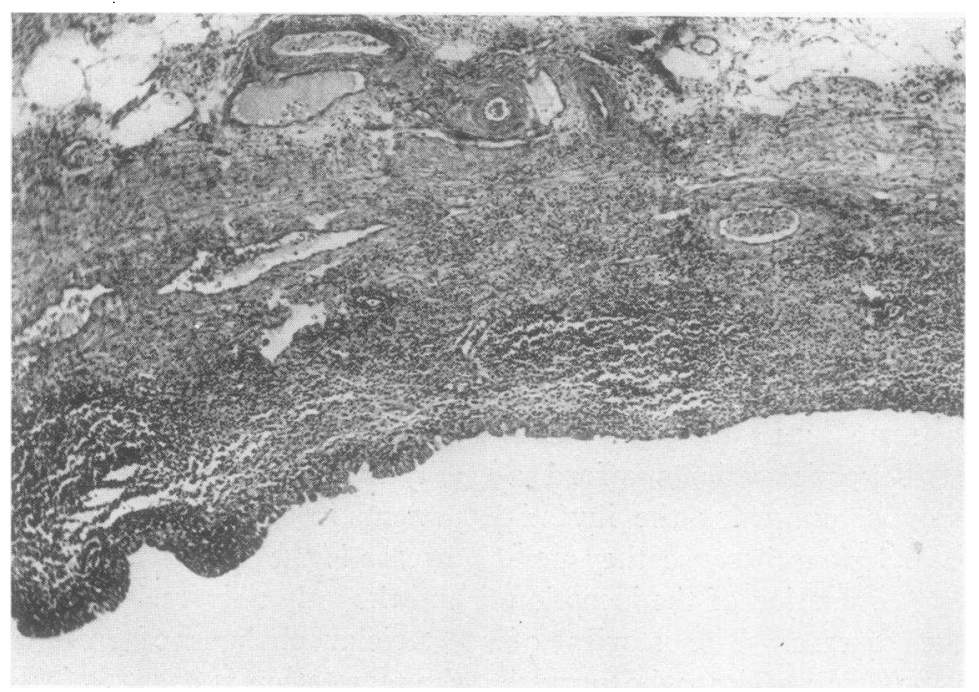

Fig. 10. Case 31841. Chronic Pyelitis.

Note partial desquamation of mucosa and extensive cellular infiltration. Hematoxylin-eosin stain; $\times 60$. 


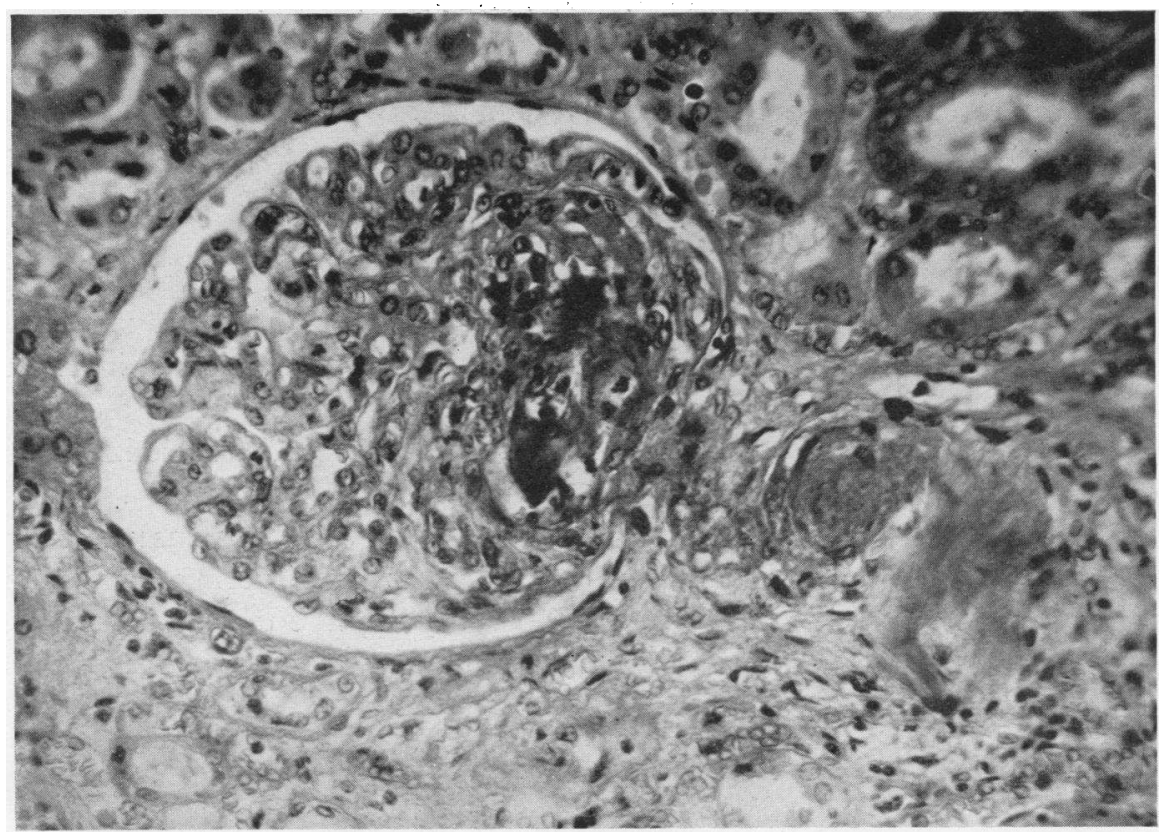

Fig. 11. Case 58750. First Pregnancy Terminated Spontaneously at 7 Months in 1926, after Period of Vomiting and Edema.

Pregnancies in 1927 and 1929 terminated, like the first, in spontaneous abortions at 7 months. Toxemic symptoms more severe with each pregnancy. Dyspnea and orthopnea in 1931, followed by marked symptoms of renal and cardiac decompensation with hypertension. Photomicrograph showing fibrin-like material in glomerular tufts; thickening of afferent arteriole. Hematoxylin-eosin stain; $\times 225$.

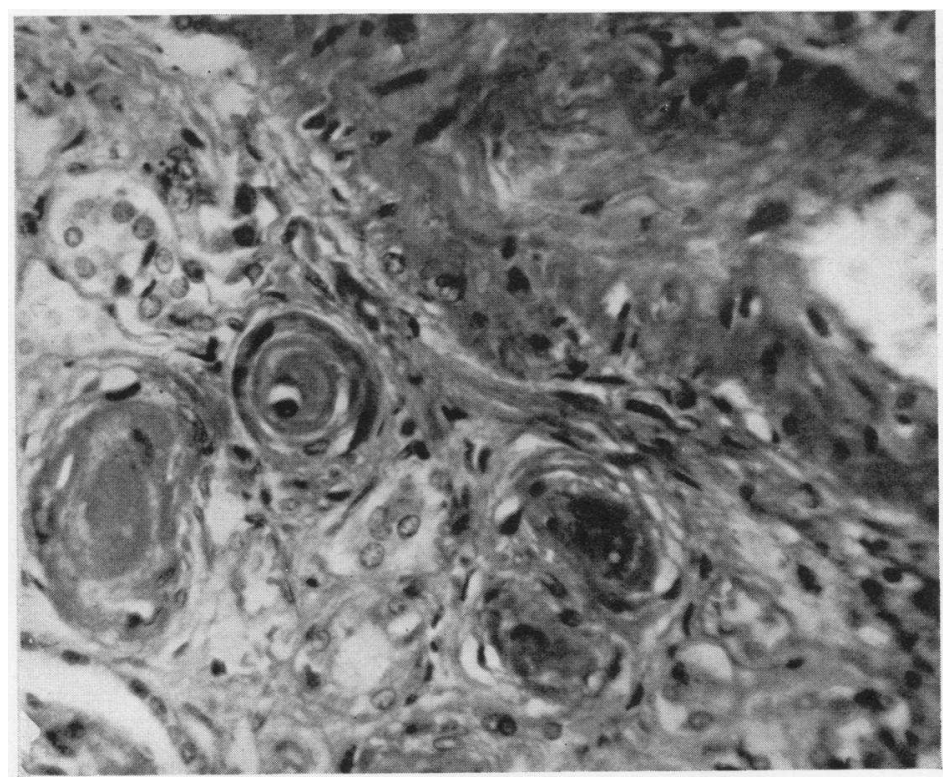

Fig. 12. Case 58750. Group of Greatly Thickened Arterioles in Renal Cortex.

Hematoxylin-eosin stain; $\times 250$. 
rangement has been discovered. The changes in the arterioles, like those in the renal parenchyma, in mild or early cases would have to be entirely reversible and therefore could not be profound. Such should be the Anlage of the lesions of malignant nephrosclerosis. If this argument is reasonably sound, the changes in the kidneys, liver and vessels in toxemias should be looked upon as tissue responses to some general stimulus, comparable to the reactions of rheumatic fever or glomerular nephritis. Possibly in many cases the analogy can be carried further; the stimulus which elicits the response may be an infection, acting not directly upon the kidney by bacterial invasion, but invoking the tissue reaction from some remote local focus. This hypothesis is not inconsistent with the nature of the lesions of malignant nephrosclerosis which, even when fully developed, suggest degeneration far more than they do inflammation.

It is not intended to imply that there is any exclusive relation between toxemias of pregnancy and malignant nephrosclerosis. This would be absurd since the latter disease draws no sharp sex line. Pregnancy is pictured throughout merely as a state of temporary physiological disequilibrium which determines a predisposition to certain pathological conditions and, when these have developed, lends them a distinctive coloration. Plausible explanations can be found for some features of the predilection and the distinctive coloration. Physiological hydronephrosis, for example, obviously predisposes to pyelitis and prevents proper drainage and elimination of infection. Physiological hypoproteinemia makes albuminuria peculiarly vicious and enhances the tendency to edema. Other disturbances of equilibrium could be cited, such as the reduction of serum sodium; but little can be gained as yet by pursuing the subject further along these lines because sufficient facts have not yet been collected to complete the story.

\section{SUMMARY AND CONCLUSIONS}

1. Case histories and necropsy findings on 23 patients who died as a result of the direct or remote effects of pregnancy toxemias are reported.

2. Although characteristic tubular and glomerular lesions were usually found in the kidneys of patients who died in the acute stages of toxemias with eclamptic syndromes, these lesions, like hepatic necroses, were not found exclusively in eclampsia.

3. Eclampsia could not be distinguished from other toxemias on the basis of either pathogenesis or morbid anatomy.

4. Lesions of "malignant nephrosclerosis" were enicountered with frequency.

5. Both acute nephritis of infectious origin and antecedent vascular disease apparently gave rise to toxemias, which sometimes had eclamptic manifestations.

6. A great variety of vascular or renal diseases may act as predisposing causes for toxemias; pregnancy appears to give them a distinctive coloration and an explosive character.

PROTOCOLS

Case $A 39242$

(For details of history see (1), Case 1.) Pyelitis appeared early in the first pregnancy, which culminated, during delivery, in eclampsia which proved rapidly fatal.

Necropsy. The uterus rose $14.5 \mathrm{~cm}$. above the symphysis pubis in the midline. It was boggy to palpation and was covered by a smooth, glistening peritoneal surface. On section the endometrium was quite red; there was no retained placental tissue.

The right kidney weighed 175 , the left 170 grams, both presenting an identical appearance. The renal pelves were considerably dilated and encroached to a moderate degree upon the parenchyma of the organs. The calices were irregular in size and shape and distinctly enlarged. Both ureters were dilated, beginning at a point opposite the lower poles of their respective kidneys. The dilatation of ureters, pelves and calices was more marked on the right side than on the left. The renal cortex was narrow and its architecture blurred.

The liver was a large flabby organ weighing 1933 grams. Scattered over all its surfaces externally and on section were numerous irregular pale yellow patches of softer consistency and greater friability than the adjacent tissue.

Microscopic. The epithelium lining the renal pelvis and the parenchyma beneath was infiltrated over wide zones with lymphocytes, plasma cells, eosinophilic and neutrophilic leukocytes and large mononuclear cells. Clusters of similar cells were found in the interstitial tissue of the pyramids and cortex. The tubular epithelium showed extensive degenerative lesions, most marked in the convoluted tubules, which varied from simple cloudy swelling to complete necrosis and desquamation (Figure $1)$. On the whole the glomeruli were anemic, but wide variations were encountered in this respect. Many seemed to be increased in size. In nearly all there was thickening of the basement membrane of the capillary 
endothelium, so marked in some instances as to obliterate completely the capillary lumina (Figure 2). In some, massive deposits of pink-staining, fibrin-like material replaced entire capillary tufts and produced an appearance similar to that seen in so-called malignant nephrosclerosis (Figure 3). An occasional glomerular space contained desquamated epithelial cells. In the right kidney there were small scars in the cortex and a few hyalinized glomeruli which were attributable to the hydronephrosis. No definite vascular lesions were found in either kidney.

The architecture of the liver was altered by a distortion of the cellular columns, which was most marked in the periportal zones. The cells of these columns contained granular cytoplasm and vacuoles. Sometimes they were entirely necrotic in rather wide areas not strictly limited to the periphery of the liver lobules. There were no associated hemorrhages, and the periportal vessels were not thrombosed.

\section{Case $A 1714$}

(For details of history see (1), Case 2.) During first pregnancy in 1929 in bed 7 weeks before delivery with edema. Near the end of second pregnancy, in 1931, eclampsia, after 10 days of extreme urinary frequency and 7 days of edema. Died within 24 hours.

Necropsy. The uterus was enlarged to the size of an eight months' pregnancy. The fetus occupied a normal position with the head at the cervix. The placenta was attached normally at the fundus of the uterus.

The kidneys, which weighed 250 and 275 grams respectively, had a homogeneous brown color externally, and their cortices were increased in width to $10 \mathrm{~mm}$. Small hemorrhages were present beneath the epithelial lining in several of the renal calices. All the calices, the renal pelves and ureters but particularly those on the right, were dilated. The dilatation began at the pelvic brim bilaterally.

The liver weighed 2400 grams, was firm in consistence and had externally a mottled hemorrhagic appearance. When the liver was sectioned, the hemorrhages appeared irregular in outline and varied greatly in size, obscuring the lobulation.

Microscopic. Small numbers of leukocytes were present beneath the epithelium of the renal pelvis. The interstitial tissue of the pyramids was edematous and infiltrated with small numbers of leukocytes and lymphocytes. Occasionally, the lumina of the straight tubules contained casts of cellular debris, amorphous granular material and polymorphonuclear leukocytes. Throughout the kidney, in the epithelium lining the convoluted tubules, there was a degenerative change, which consisted of cloudy swelling and granulation of the cytoplasm. Desquamation of these cells, however, was not extensive. All the glomeruli showed mild to moderate thickening of the basement membrane between capillary endothelium and lining epithelium. Most glomeruli appeared anemic, but in a few there were hemorrhages, sometimes extending into the glomerular spaces and appertaining convoluted tubules. Capillary tufts in occasional glomeruli seemed to be replaced by fibrin masses. The afferent arterioles and other vessels of arteriolar size had greatly thickened, acellular wells.

In the liver were numerous focal hemorrhages, chiefly in the vicinity of periportal zones. These varied in size from a few extravasated red cells to masses which involved several contiguous lobules. Necrosis of liver cells accompanied the hemorrhagic lesions. Fragmented cells were seen in the interiors of leukocytes and large mononuclear cells. Large collections of lymphocytes were present around the periportal vessels, but none of the latter were thrombosed.

\section{Case 3666}

(For details of history see (1), Case 3.) In 1919 second pregnancy terminated at 8 months for toxemia. In July, 1921, miscarriage at 5 months, at which time there was distinct edema. In November, 1921, during third pregnancy, developed cold in chest with cough, followed a few days later by chills, dyspnea, orthopnea, headache, vomiting, pains in chest, limbs and back, and blurred vision. The condition became worse steadily until death 4 weeks after the onset of symptoms.

Necropsy. Both kidneys were small, the right weighing 55 grams and the left 31 grams. Their external surfaces were irregular and scarred. The pelves were greatly dilated; the cortex and pyramids were compressed to form a rim only 5 to $10 \mathrm{~mm}$. in width. Cortical striations could be seen not at all or only with great difficulty. Both ureters were dilated, but the urinary bladder was small and contracted; its wall measured $12 \mathrm{~mm}$. in thickness. The entire urinary tract was filled with thick, purulent material. The mucosa of the pelves, ureters and bladder was thick, opaque and contained numerous small hemorrhages.

The heart was increased in size, weighing 300 grams (body weight $38 \mathrm{kilos}$ ), and the papillary muscles were hypertrophied. There was no evidence of chronic passive congestion of the viscera and no edema nor ascites.

Microscopic. Extensive scars infiltrated with numerous lymphocytes and plasma cells replaced much of the renal parenchyma. Enormously dilated tubules with flattened epithelial cells and coagulated material in their lumina alternated with atrophic tubules. The majority of the glomeruli were replaced by densely hyalinized connective tissue; a few, less severely injured, had thickened capsules and an occasional adhesion between tuft and capsule. Both arteries and arterioles had concentrically thickened walls which reduced the size of their lumina.

The mucosa of the pelves, ureters and bladder was much thickened in some places. In others it was necrotic or desquamated and replaced by chronic granulation tissue containing numerous capillaries, lymphocytes and plasma cells which extended into the submucosa (Figure 4). A hemorrhagic exudate was seen on the free surface.

\section{Case 79045}

Born 1899. Patient is reported to have been entirely well during pregnancies in 1915, 1918, 1920, 1923, 1926 and 1927. All except the last, which ended in a pre- 
mature delivery at 7 months, resulted in living children. Her mother died at 40 in childbirth, her father at 58 of "acute indigestion"; one sister at 44 had hypertension. She was first seen in the prenatal clinic March 21, 1929, three and a half months before term, with blood pressure $180 / 120$, moderate edema of the ankles, heart slightly enlarged to the left, but no albuminuria. April 4, the blood pressure was only $130 / 80$, but it was again $170 / 120$ on April 22, still without albuminuria. April 29, she was admitted to the hospital in labor and delivered of a dead premature fetus. May 12, when she was discharged, the blood pressure was still 150/94. Her course in hospital was uncomplicated except that her temperature rose to $100.2^{\circ}$ on May 4. She was again seen in the prenatal clinic April 16, 1931, in the sixth month of pregnancy. She had suffered from nocturia without diurnal frequency, urgency or burning, since the onset of pregnancy. April 9, she was seized with headache and began to vomit continuously. She had also been troubled with palpitation and with precordial pain which radiated to the back and down to the left hip. When seen, her blood pressure was $220 / 140$, her heart was enlarged to the left and a soft diastolic murmur could be heard over the whole precordium, especially over the aortic area, and over the vessels of the neck. She also had moderate pitting edema of the legs. The optic discs were blurred and the retinal vessels tortuous. She was brought into the hospital, where she remained one week, at the end of which her blood pressure was still 156/110. Her course was afebrile. The urine contained the faintest possible trace of albumin; the blood nonprotein nitrogen was $18 \mathrm{mgm}$. per cent, phenolsulphonephthalein excretion 80 per cent. She refused to permit termination of pregnancy and sterilization. June 29, she was readmitted to the hospital in labor and was delivered of twins precipitately. Her blood pres-

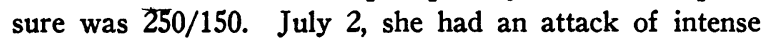
precordial pain which persisted. July 3 , she suddenly lost consciousness and stopped breathing. Although she roused for a short time, she died 30 minutes later. The urine on June 29 contained a slight trace of albumin and occasional granular casts. On June 30 the blood nonprotein nitrogen was $23 \mathrm{mgm}$. per cent; blood count, red blood cells 4.1 million, hemoglobin 70 per cent, leukocytes 5,500 .

Necropsy. The kidneys, which weighed 175 grams each, were deeply congested and swollen, without evidence of scarring. The larger renal vessels were not thickened. The pelves and ureters were not dilated.

The liver weighed 1800 grams and did not appear abnormal in the gross. Microscopically there were small foci of necrosis in the periportal regions.

The heart was greatly hypertrophied, weighing 600 grams. Fresh blood clot filled the pericardial sac and unclotted blood oozed from a small opening on the anterior surface of the ascending aorta just below the pericardial attachment. This blood had its origin from a dissecting aneurysm which seemed to arise at the site of an intimal tear above one sinus of Valsalva on the posterior wall of the aorta and extended down as far as the superior mesen- teric artery. There was only slight atheromatous change in any of the larger arteries, including the coronaries. Blood-tinged fluid was present in both pleural cavities, $200 \mathrm{cc}$. in the right and $500 \mathrm{cc}$. in the left.

The uterus projected about $10 \mathrm{~cm}$. above the symphysis pubis, but was firm and contained only fresh blood clots in its cavity.

Microscopic. Although there was extensive cloudy swelling of the epithelial cells of the renal tubules, only occasional tubules were necrotic and in still fewer did the epithelium show colloid change. All the glomeruli had thickened basement membranes beneath the lining epithelium, similar to the glomerular changes in the first two cases. There was neither endothelial nor epithelial proliferation. A few glomeruli contained fibrin masses in their tufts, resembling the glomerular changes seen in malignant nephrosclerosis. The most constant lesion was a marked hypertrophic thickening of the media of the smaller renal arteries, which involved especially afferent glomerular arterioles, but affected also the arterioles generally throughout the body. The renal pelves were free from inflammatory reaction.

\section{Case 83867}

Born in 1898, patient was first seen June 25, 1930, early in pregnancy. She was reported to have had slight kidney trouble near the end of her first pregnancy in 1921, but this she denied. In 1925 she was, however, put to bed because of "inflammation of the kidneys," high blood pressure and edema of the ankles in the seventh month of her second pregnancy, which ended prematurely with a stillbirth. Otherwise she had no history of serious illness. There had been no symptoms of renal, cardiac or vascular disease, although she had been told that her blood pressure was slightly elevated. She appeared nervous and excited, pulse very rapid, blood pressure $192 / 120$; the retinal vessels were normal; a systolic murmur was heard over the whole precordium. When she was admitted to the hospital for 6 days observation June 27 her pulse was 110, blood pressure $185 / 125$; the urine contained no albumin and only an occasional leukocyte; the blood nonprotein nitrogen was $29 \mathrm{mgm}$. per cent; blood count normal. The blood pressure, taken by competent nurses and interns on several occasions varied from 132 to $140 / 70$ to 95 , although it was found on one occasion when she was excited, as high as $164 / 110$. After discharge she remained entirely free from symptoms. Her blood pressure continued extremely variable. Although it was usually elevated, 150 to 200, when she reported to her physician, and showed a tendency to mount gradually, on occasions in her home it proved to be almost normal. The urine was consistently free from albumin. November 22 , she noticed general malaise and myalgia and the next night was seized with sudden agonizing pain in the epigastrium and between the scapulae, accompanied by nausea and vomiting. The pain and vomiting recurred at intervals during the night. When she entered the hospital November 24 her pulse was 100 , blood pressure 210/70; 
her heart was enlarged to the left, with loud, blowing systolic murmurs in the aortic area and at the apex; there was slight dulness below the angle of the right scapula. November 27 , her face was somewhat puffy, the murmurs at the apex and base grating in character; the liver was somewhat enlarged and râles were heard at the bases of both lungs. November 30 , she appeared restless, apprehensive, pale, slightly cyanotic, with labored breathing, râles all over her chest, liver considerably enlarged, but no edema. December 2, the cyanosis and dyspnea had become extreme. The temperature, which had been as high as 100 to $100.4^{\circ}$ occasionally, from the first, had reached $102.4^{\circ}$ December 1 . The heart sounds had become distant, the area of cardiac dulness had increased; the murmurs at the apex were fainter, but the to and fro hum at the base persisted. She suddenly stopped breathing early the next morning. The blood pressure varied from $140 / 70$ to $200 / 80$ quite capriciously. The urine contained much albumin, many leukocytes and casts and rare red blood cells. There was nothing unusual about the blood count except a leukocytosis 12,400 to 17,300 with 76 to 80 per cent polynuclears. November 26 , the blood nonprotein nitrogen was $29 \mathrm{mgm}$. per cent, phenolsulphonephthalein excretion 20 per cent, urine culture sterile. December 1, Streptococcus viridans was found in one blood culture; but 4 previous and 2 subsequent cultures proved sterile.

Necropsy. There were no abnormalities in either the fetus and its membranes or the uterus, which filled the pelvis and extended $18 \mathrm{~cm}$. above the symphysis pubis.

The right kidney weighed 200 and the left 100 grams. This discrepancy in weight was due to several deep scars in the left kidney, the results of healed infarcts. The pelves and ureters were not dilated and contained no exudate. There were no evidences of marked atherosclerosis in the larger renal vessels and no scars in the cortex other than those already mentioned.

The liver weighed 1725 grams and externally and on section had a nutmeg appearance.

There was marked hypertrophy of the heart, which weighed 500 grams, and slight thickening of the mitral valve with shortening of its chordae tendineae. A large quantity of unclotted blood, filling the pericardial sac, was seen to emanate from a small discolored zone on the posterior surface of the ascending aorta. This vessel was the seat of a dissecting aneurysm which appeared to arise from a transverse break in the intima above the posterior cusp and extended down into the common iliac arteries and up into the left common carotid artery. There was no free fluid in the peritoneal cavity, but the pleural cavities contained 200 and $150 \mathrm{cc}$. of clear serous fluid.

Microscopic. There was no cellular inflammatory process in any part of the kidneys, including the pyramids and pelvis. The epithelium lining the convoluted tubules showed cloudy swelling of a degree sufficient to occlude the lumina frequently, but there was no epithelial necrosis or desquamation. All the glomeruli appeared to be increased in size, filling their respective glomerular spaces; yet they were relatively acellular. Many of the capillary tufts had a wire-loop appearance, as the result of thick bands of homogeneously stained material between the rows of epithelial and endothelial cells. Some tufts appeared completely hidden by the deposition of an amorphous material like fibrin or coagulated fluid. The renal arterioles were all nearly occluded by a thickening of their media and the same vascular change was present in nearly all the other viscera. The tubular and glomerular lesions which were more acute in nature and similar to those found in the eclamptic cases, were superimposed on this older vascular disease.

Throughout the liver large zones of necrosis were seen, located principally in the periportal zones and for the most part unasscoiated with hemorrhage.

\section{Case 81551}

Born 1902. Past history unknown, except that her mandible was removed in 1910. About October 28, 1929, six weeks before term, in her first pregnancy, her ankles swelled. November 7 , slight vaginal bleeding began. November 9, she was seized with sudden abdominal pain and vomited. Presumably she also had a convulsion. When she was brought to the hospital a little later she was restless, tossing, complaining of headache and abdominal pain, with blood pressure 210/140, marked pitting edema of the feet, ankles, legs and back, urine containing large amounts of albumin and casts, but no bacteria. She died in a conzulsion before effective treatment could be instituted.

Necrospy. The gravid uterus filled most of the maternal pelvis and extended into the abdominal cavity to the level of the second lumbar vertebra. There were nearly 3 liters of slightly blood-tinged fluid in the peritoneal cavity.

The kidneys, which weighed 175 grams each, were not granular and their pelves and ureters were undilated.

The liver weighed 1800 grams and presented numerous large and small hemorrhages externally and on section. These were largest in the vicinity of the hepatic ligaments and gallbladder.

The heart was not hypertrophied, its weight being 300 grams (body weight 69 kilos).

Microscopic. There was no inflammatory reaction in the renal pelves and pyramids. Casts of desquamated epithelial cells were found in the collecting tubules. The epithelial cells of the convoluted tubules showed marked cloudy swelling. Some lacked distinct cell outlines and nuclei and had coarse granules in the cytoplasm. Most glomeruli appeared anemic. The tufts had sharp, unusually prominent outlines due to a thickening of the substance between capillary endothelium and lining epithelium. There was no epithelial or endothelial proliferation and no capillary occlusion. The renal arterioles did not have thickened walls.

In the liver the hemorrhagic zones were limited almost without exception to the periportal regions. Here the liver cells were crowded, flattened and necrotic, 
occasionally the necrosis was found in small foci which were free from hemorrhage. Homogeneous, pink-staining material resembling hyalin or fibrin filled some of the periportal vessels.

\section{Case 61702}

Born 1893. Patient was admitted to the hospital September 10,1927, 35 weeks gravid. Three previous pregnancies are reported to have been entirely normal. For a month she had suffered from frequent headaches, dizziness and slight edema of the feet. September 8, she developed photophobia and just before admission became suddenly blind. On admission she was restless and apprehensive, but rational, with marked tenderness over the frontal and maxillary sinuses, extreme retinal edema, blood pressure $170 / 85$, moderate generalized subcutaneous edema, leukocytosis, urine containing much albumin, a few casts and leukocytes. A little later she had a severe convulsion, lasting 30 minutes, but after this she improved so that she was able to take fluids the next day. However, her temperature had risen to $101^{\circ}$. September 12 , her blood pressure fell to $130 / 40$ and the temperature became normal. At 8:00 p.m. the fetal heart suddenly ceased to beat. A Voorhees bag was inserted and 4 hours later she was delivered of a premature child which lived less than 24 hours. September 15, the temperature rose to $100^{\circ} \mathrm{F}$, the pulse was about 100 , blood pressure $140 / 100$. Her general condition became progressively worse. September 20, she sank into coma; September 21 , she exhibited signs of cerebral irritation and focal pneumonia; September 22, she died with a terminal rise of temperature to $106^{\circ}$. The Van den Bergh test, September 10 , was entirely negative. Spinal fluid obtained after death, by puncture of the cisterna, was xanthochromic and contained many red blood cells.

Necropsy. Small, fresh hemorrhages were seen on the serosal surfaces of the ovaries and uterus. There were no thrombi in the vessels of the broad ligaments. The uterus was soft and enlarged and on section revealed a large blood clot which was adherent to the anterior surface of the endometrium.

In the cortex of the kidneys, which weighed 175 grams each, there were minute fresh hemorrhages. The right kidney also contained a small white infarct. The renal pelves and ureters were not dilated and were free from purulent material.

The liver weighed 1800 grams and presented a normal appearance in the gross and on microscopic examination.

Numerous large and small hemorrhages were seen in both lungs. Leading to a few of these which were raised above the pleural surfaces, could be traced blood vessels which were occluded by friable blood clots. In a few instances these hemorrhagic infarcts extended to the pleural surface which, however, was still free from exudate and fluid. The right adrenal was hemorrhagic and twice the size of the left which weighed 25 grams. Recent small hemorrhages were scattered in the white matter of both cerebral hemispheres and in the left thalamic nucleus.

Microscopic. Several of the larger uterine veins were occluded by thrombi which in some instances were in process of organization. These and other vessels were surrounded by small mononuclear cells resembling lymphocytes and by small numbers of leukocytes. The source of the emboli to the lungs, brain, right kidney and adrenal appeared to be these uterine thrombi. The infarcts in these organs were still quite recent, with little evidence of organization and none of suppuration.

The renal pelves were devoid of inflammatory exudate. In the tubules, especially their convoluted portions, was noted extensive injury consisting of marked swelling of the epithelium which often led to tubular occlusion. Numerous necrotic epithelial cells were desquamated into the lumina. All the glomeruli showed some thickening of the basement membrane and a relative acellularity. None of the capillary loops were occluded. Small hemorrhages were present in the interstitium of the cortex. The renal vessels, large and small, were not altered in any way.

\section{Case 9354}

Born 1898. July 24, 1922, two months before term, in her first pregnancy, patient had a normal blood pressure and no albuminuria. Shortly after this she developed edema of the feet which gradually extended to the legs; and about August 5 extreme nocturnal urinary frequency. August 12, she awoke with a headache which increased steadily during the day. At 4:00 p.m. she had a convulsion, followed by 3 more in rapid succession. At 7:00 p.m. when she entered the hospital she was conscious, but restless and breathless. She had generalized edema, a totally irregular heart, blood pressure $142 / 115$. At 8:00 p.m. the blood pressure was 175 . Convulsions continued at intervals. At 10:00 p.m. the fetal heart became inaudible. At 3:00 a.m., August 13, she lapsed into coma after a convulsion. At 4:00 a.m. she was delivered of a dead child, a little later the blood pressure fell sharply to $90 / 55$, and at 7:00 a.m., after her 12th convulsion, she died. Urine obtained by catheter on admission contained much albumin, many casts, and masses of red blood cells and leukocytes. She did not urinate again, and only a few drops could be obtained by catheter after death. The temperature rose to $101^{\circ}$ a few hours before death. Blood count: red blood cells 5.1 million, hemoglobin 85 per cent, leukocytes 30,800 , polynuclears 85 per cent. Blood nonprotein nitrogen 28 mgm. per cent.

Necropsy. A subserous myoma measuring $5 \mathrm{~cm}$. in diameter was found on the posterior wall of the greatly enlarged uterus. The uterine cavity was filled with a fresh blood clot, but otherwise was not unusual.

The left kidney weighed 175 and the right 150 grams. Both showed the remains of fetal lobulations and were pale and swollen. The pelves and ureters were not dilated.

The liver weighed 1875 grams. Parts of it were soft and flabby, yellow in color and indistinctly lobulated.

A recent hemorrhage some $2 \mathrm{~cm}$. in diameter was present in the lower lobe of the right lung. 
Microscopic. There was a moderate amount of granulation and irregularity of the epithelium of the convoluted and collecting tubules of the kidneys. Some tubules were obstructed by the swollen epithelium, some were filled with granular material and some with numerous well preserved red blood cells. The glomeruli were not abnormal. There was no pyelitic process and the renal vessels were not thickened.

There were numerous zones in the liver in which the hepatic cells were poorly stained. Some of the cells had granular cytoplasm and small, pyknotic nuclei. There was no definite necrosis and no hemorrhage.

A few cortical extravasations of red blood cells were found in the adrenals.

\section{Case 60242}

Born 1905. Patient was reported to have been treated for kidney trouble for about a year in 1923, but the nature of the disease is not known. April 8, 1927, 12 days after the birth of her first child, although labor and delivery had apparently been uncomplicated, she was seized with sudden cramp-like pain in the lower abdomen, followed by a chill. The pain lasted only a short time. On the morning of April 9 she had a severe headache, but took some food. Later in the day she vomited several times, the last times bloody material. Meanwhile she became increasingly languid, finally lapsing into stupor with incontinence of urine. She was brought to the hospital in a comatose state, pale, with slight puffiness of the face, rapid, shallow breathing, pulse 140 , blood pressure $80 / 50$, with no demonstrable lesions in heart, lungs or abdomen. She did not respond to infusions, transfusions and other stimulative measures. April 10, she appeared slightly jaundiced. Later in the day she developed strabismus and ptosis. She continued to vomit blood-stained material. September 11, she appeared extremely jaundiced, cyanotic, restless, with gasping respirations, pulse 160 , blood pressure $64 / 52$, tenderness over the whole right side of the abdomen. At noon she suddenly vomited blackish material and died a few minutes later after some convulsive movements. Urine, obtained by catheter, contained much albumin and moderate numbers of leukocytes. Blood count: red blood cells 4.9 million, hemoglobin 85 per cent, leukocytes 22,200, polynuclears 94 per cent. Blood culture negative. Spinal fluid (postmortem) clear, globulin \pm , leukocytes 121 , mononuclear 118 , polynuclear 3 , red blood cells 152 , culture sterile, Wassermann negative. Blood nonprotein nitrogen, April 11, $98 \mathrm{mgm}$. per cent. The temperature, on admission, $105^{\circ}$, was continuously elevated until death.

Necropsy. Although it was still increased in size and soft, no further abnormalities of the uterus were discovered either in the gross or on microscopic examination. This was true as well of the tubes and broad ligaments.

The right kidney weighed 150 and the left 125 grams. Both were unusually pale and appeared somewhat swollen. Their pelves and ureters were not abnormal.

The liver weighed 1425 grams and appeared normal macroscopically. There were likewise no lesions in the brain.

Misroscopic. There was no cellular reaction in the renal pelves and pyramids. Extensive edema was present in the connective tissue throughout the cortex and medulla. The renal tubules contained a flattened epithelium even in the convoluted portions, but the cytoplasm was markedly granular. The nuclei were often absent or obscured and many cells were desquamated. This extensive tubular lesion overshadowed the milder glomerular changes which consisted of an increase in their size without an apparent increase in their cellularity and of a slight thickening of the connective tissue between capillary endothelium and lining epithelium. The renal vessels were not thickened.

Throughout the liver were seen numerous foci of necrosis and hemorrhage (Figure 5). These were invariably of small size and almost invariably located in periportal regions. Small numbers of leukocytes were found among the necrotic liver cells. The periportal vessels did not appear occluded.

\section{Case $A 32601$}

Born 1896. Patient is reported to have had "no serious illnesses nor operations." Previous pregnancies in 1925, 1928 and 1931, the last ending in abortion, are said to have been uncomplicated. In October 1934, about 3 months before term, her feet began to swell and after this she suffered from slight headaches. When seen, December 19, she had edema of the abdominal wall and legs, blood pressure 160/110. The next morning at 5:00 a.m. her pulse had risen to 120 and she had a slight cough. By 8:00 a.m. her sputum was bloody, pulse 144, breathing rapid, skin clammy, râles were audible at the left base and in the right scapular region. Dyspnea and cyanosis increased steadily. On the morning of December 21 , râles became audible over the whole chest, the pulse became weak and irregular, and the blood pressure fell to $90 / 60$. She died a few hours later. The temperature remained normal until a few hours before death, when it rose to $102^{\circ}$. The urine contained much albumin and moderate numbers of red blood cells and leukocytes. Blood count: red blood cells 3.9 million, hemoglobin 60 per cent, leukocytes 16,500 , polynuclears 92 per cent.

Necropsy. The gravid uterus contained a twin pregnancy, but was otherwise not unusual.

The right kidney weighed 216 and the left 182 grams. Both were pale, flabby, and considerably swollen. Their pelves were not dilated, but the right ureter was approximately 3 times the diameter of the left. This dilatation extended from the brim of the maternal pelvis to the renal pelvis. The wall of this ureter was also considerably thickened.

The liver weighed 1985 grams and on section revealed a sprinkling of small, bright red hemorrhages.

Both lungs were extensively consolidated with pneumonia and were deep red in color.

Microscopic. Although there was widespread cloudy swelling of the renal tubular epithelium, few of the 
cells were desquamated. Nevertheless, the lumina were filled with an amorphous granular material and occasional red blood cells. The glomerular tufts were unusually prominent by virtue of thickened subepithelial connective tissue, which produced the "hair-pin" appearance often described in eclampsia. The glomeruli were large and filled their respective spaces without any apparent increase in their cellularity. The renal blood vessels did not have thickened walls.

Numerous foci of cellular necrosis were found in the liver. Some were quite small while others involved portions of several adjacent liver lobules. They occurred relatively infrequently in the periportal zones and had no special site of predilection within the lobules. Only infrequently were they hemorrhagic, but almost all contained leukocytes.

\section{Case 71013}

Born 1895, colored, patient was admitted to the hospital August 7, 1928. Four months earlier pregnancy was terminated because of orthopnea, dyspnea and edema of the feet. The symptoms, however, had increased steadily after this. On admission she was acutely sick, confused and semistuporous, with orthopnea, dyspnea and massive edema of the lower part of the trunk and the lower extremities. The left tonsil was much enlarged, the posterior cervical lymph nodes palpable. There was some fluid in the left chest, more in the right, with râles audible above the fluid. The heart was enlarged with a harsh systolic murmur and a rough diastolic murmur at the apex, the liver was enlarged almost to the navel. She seemed to improve under treatment for a few days; but it was impossible to restore cardiac and renal function and to eliminate edema. August 26, she sank into a stupor and died. The blood pressure, August 25, was 230/160. She had a slight irregular fever. The Wasserman reaction was $4+$ cholesterol, 0 alcoholic antigen. The urine, of low specific gravity throughout, contained much albumin, many leukocytes and casts. Blood count: red blood cells from 4.4 to 1.6 million, hemoglobin from 60 to 30 per cent; leukocytes were only 8,000 on August 9 and 17, but 20,200 on August 25. Blood nonprotein nitrogen: August 8, $89 \mathrm{mgm}$. per cent, August 23, $187 \mathrm{mgm}$. per cent. Phenolsulphonephthalein excretion, August 21, 2 per cent. Cultures of fluid from thorax and abdomen were sterile.

Necropsy. The peritoneal cavity contained about 1500 cc. of clear serous fluid in which were floating flakes of fibrin, and each of the pleural cavities contained about $500 \mathrm{cc}$. of similar fluid.

Both kidneys, which weighed 100 grams each, were edematous and pale and had numerous cortical scars. The pelvic mucosa was pale and intact, but appeared somewhat thickened. The pelves and ureters were not dilated.

The external surfaces of the liver were covered with strands of fibrin which were present also in the peritoneal cavity. The organ weighed 1400 grams and was mottled yellow and red in the pattern of a "nutmeg" liver.
Small hemorrhages were scattered beneath Glisson's capsule.

The hypertrophied heart weighed 500 grams (body weight 75 kilos). There were no valvular lesions to account for this hypertrophy and no obvious arteriosclerotic lesions were found in any of the organs.

Microscopic. The renal pelves were lined by a hyperplastic mucosa like that seen in chronic pyelitis, but there were few inflammatory cells in or beneath the mucosa. Extensive scars infiltrated with small mononuclear cells marred the renal architecture (Figure 6). These scars undoubtedly accounted for the numerous shrunken, atrophic renal tubules which occurred in groups adjacent to greatly dilated and hypertrophied tubules. Surprisingly large numbers of tubules were filled with granular and cellular casts in which polymorphonuclear leukocytes predominated. The glomeruli were much less extensively injured. Many were hypertrophied and small numbers were completely hyalinized. In rare instances adhesions were seen between glomerular tufts and Bowman's capsule. There was simple hypertrophy of the media of the renal arteries. The smaller arterioles had such greatly thickened walls that the lumina were frequently obliterated.

The liver lobules showed extensive necrosis and hemorrhage in the central vein regions. With this picture of chronic passive congestion there was no demonstrable fibrosis.

\section{Case 18925}

Born 1900. Patient was admitted to the hospital in labor in the 8th month of pregnancy, June 14, 1923. She is reported to have had edema for 2 months in 1920, with recurrences in the summers of 1921 and 1922. For a month before admission she had moderate, generalized edema; for 2 weeks headaches, dizziness and blurred vision. On admission she presented moderate, generalized subcutaneous edema, blood pressure 180/136. Because she was bleeding from the uterus a Voorhees bag was inserted. A little later she was seized with severe epigastric pain, vomited, and went into a state resembling shock, with air-hunger, although her blood pressure fell only to $150 / 118$. She improved after a transfusion, but her temperature rose to $100^{\circ}$ during the day and on succeeding days rose still higher, varying from 100 to $104^{\circ}$. June 15 , she became cyanotic. The edema increased, respirations became labored; the abdomen was distended, everywhere tender, with dulness in the flanks, and signs of fluid appeared in the right chest. She was almost anuric, and the edema increased steadily. She sank into coma and died June 20 . The urine contained much albumin, casts, pus cells and red blood cells. Blood count: red blood cells 2.9 to 2.1 million, leukocytes 30,600 to 25,200 , polynuclears 89 to 93 per cent. Blood nonprotein nitrogen June 14, 51 mgm. per cent; June 15, 99; June 18, 181 ; June 20, 221.

Necropsy. The uterus was enlarged, rising slightly above the brim of the maternal pelvis. The Fallopian tubes were deeply congested. There were $150 \mathrm{cc}$. of 
cloudy fluid in the peritoneal cavity whose surfaces, however, were smooth and glistening.

The kidneys weighed 200 grams each. They were pale organs from which the capsules could be stripped readily, exposing smooth surfaces covered with great numbers of petechiae. Neither the pelves nor ureters were dilated.

The liver was very large, weighing 2200 grams. It contained numerous large central zones of necrosis which were yellow in color surrounded by peripheral zones of hemorrhage. Similar lesions were found in the lungs and colon.

Two large, cauliflower-like masses were attached to the mitral valve of the heart which weighed 275 grams. One of these was quite firm and gray in color, the other was red and friable.

Microscopic. The endometrial surface of the uterus was covered by blood clot which was infiltrated with leukocytes and contained great masses of bacteria. Extensive hemorrhages were present throughout the uterine musculature. Many vessels were filled with thrombi, some of which were partially organized.

There was extensive destruction of the tubular epithelium of the kidneys. Many tubules were completely filled with granular material which was often mixed with mononuclear cells and leukocytes. Some contained casts of red blood cells. The interstitial tissue was edematous and contained both cellular exudate and bacterial masses. All the glomeruli were swollen and filled their spaces completely. Some were hemorrhagic and others contained bacterial emboli in their capillary loops. Many of the renal vessels were congested, but they were not otherwise altered. The pelvic mucosa appeared normal.

Bacterial emboli in large numbers were seen in the liver, lungs and colon. Microscopically, infected infarcts were found in all these organs.

\section{Case 33564}

Born 1905. Patient was admitted to the hospital June 13, 1924, about the sixth month of her first pregnancy. For two months she had been extremely irritable and nervous, with increasing awkwardness in manual movements and twitching of the facial muscles. June 6 , she suddenly developed extreme weakness of the legs, and a little later grimacing and difficulty in speaking. June 10 , she was forced to bed by weakness of the legs, pains in the pelvis, abdomen, loins and hips. June 13, she gradually sank into coma. On admission she was in deep coma, moaning, restless and twitching, temperature $103.4^{\circ}$ pulse 160 , blood pressure $120 / 86$, with rapid, labored breathing, tracheal râles, slight cyanosis, dry coated tongue, rigid neck and spine, apical thrill and murmur, doubtful Kernig sign and absence of deep reflexes. Her condition did not improve. The temperature rose steadily to reach $107^{\circ}$ before death on June 15. Urine contained much albumin, many casts, and occasional red blood cells and leukocytes. Blood count: red blood cells 5.2 million, leukocytes 12,400 , polynuclears
83 per cent. Blood culture sterile. Spinal fluid clear, but under increased pressure. Blood nonprotein nitrogen $29 \mathrm{mgm}$. per cent.

Necropsy. The gravid uterus filled the maternal pelvis and extended up to the level of the umbilicus. The fetus and fetal membranes presented no abnormalities.

The kidneys, which weighed 200 grams each, were swollen and congested. A few petechiae were seen in the mucosa of the renal pelves. The latter as well as the ureters were not dilated.

A row of verrucous vegetations were present along the line of closure of the mitral valve. The heart, which weighed 225 grams, presented no other abnormalities.

Lack of permission prevented examination of the brain.

Microscopic. The renal tubular epithelium was swollen and granular and in some places had undergone actual necrosis. The tubules contained amorphous granular debris, desquamated cells and erythrocytes. The interstitial tissue was edematous and here and there contained collections of small round cells. There was marked congestion of the glomeruli whose capillary endothelium was swollen. Some glomerular capillaries appeared closed with thrombi. Other than congestion the renal vessels presented no abnormalities. The pelvic mucosa was normal.

Typical Aschoff bodies were found in small numbers throughout the myocardium. The mitral verrucae consisted of hyalin thrombi superimposed on an organizing exudate composed of round cells and leukocytes. Bacteria were not present.

The liver was normal histologically.

\section{Case 63494}

(For details of history see (1), Case 4.) In 1928, just after delivery of first child went into eclampsia. Puerperium febrile, associated with pyuria. Relapse, after discharge, with fever, headache, lumbar pain and general malaise. Ten weeks after delivery, hypertension. Readmitted 5 years later with advanced renal and cardiac failure and died after 5 weeks.

Necropsy. The right kidney weighed 70 and the left 60 grams. The cortical markings were indistinct and much of the parenchyma seemed to have been replaced by fibrous connective tissue. The surfaces of the kidneys were markedly granular. Both kidneys contained a superabundance of peripelvic fat although the pelves were not dilated. Nor were the ureters unusual except for their greatly thickened walls.

There was moderate cardiac hypertrophy, the heart weighing 450 grams (body weight 74 kilos). There were no valvular nor vascular lesions. An excess of clear, yellow, serous fluid $(175 \mathrm{cc}$.) was found in the pericardial sac. There were $125 \mathrm{cc}$. of similar fluid in the left pleural cavity; the right cavity was obliterated by fibrous adhesions.

Microscopic. The architecture of the kidney was distorted by a tremendous increase of connective tissue. In many zones the glomeruli were completely hyalinized and their associated tubules were atrophic. Some glo- 
meruli were greatly hypertrophied and their tubules were dilated and lined by tall columnar epithelium. The cytoplasm of some of the cells lining these tubules showed colloid change. There was an extensive lymphocytic infiltration throughout the interstitial tissue. The blood vessel walls were thickened, but their lumina were patent. The picture presented by both kidneys was that of advanced hydronephrosis. The pelvic mucosa was desquamated in many places and its place was occupied by lymphocytes, plasma cells and large mononuclears (Figure 7). The walls of both ureters were greatly thickened as the result of an increase of fibrous tissue. Beneath and replacing the ureteral mucosa were collections of lymphocytes, other mononuclear cells and plasma cells (Figure 8).

The liver was normal.

\section{Case 44154}

(For details of history see (1), Case 5.) In 1912 pyelitis in seventh month of first pregnancy. After this, complaint of recurrent pains in back and abdomen with later hypertension, renal and cardiac failure until death in 1935.

Necropsy. There were generalized subcutaneous edema, $800 \mathrm{cc}$. of clear, amber fluid in the peritoneal cavity and $300 \mathrm{cc}$. of similar fluid in the right pleural cavity. The left thoracic cavity was obliterated by fibrous adhesions.

The right kidney weighed 24 grams and the left 60 grams. The external surfaces of both were scarred and granular. The right kidney consisted largely of its pelvis and calices with only a narrow rim of cortical tissue. On the left side there was no obvious pelvic dilatation. Both ureters were undilated. Large subintimal atheromatous plaques were present in both renal arteries, but they were more numerous in the right.

The liver weighed 1230 grams and showed numerous small hemorrhages externally and on section.

There was cardiac hypertrophy, especially of the left ventricle, without cardiac dilatation, the heart weighing 395 grams (body weight 50 kilos).

The wall of the entire colon was thickened by edema and its mucosa was discolored and ulcerated in numerous places. The ulcerations surrounded small islands of preserved mucosa which resembled polypoid structures.

Microscopic. Both kidneys were tremendously scarred and contained little normal parenchyma. The scars were infiltrated with large collections of lymphocytes and other mononuclear cells. The tubules were either shrunken and filled with coagulated homogeneous material or were greatly dilated and lined by hypertrophied epithelium. The majority of the glomeruli were completely hyalinized. Both large and small arteries had markedly thickened walls with hyperplastic intimal coats and minute lumina. Several vessels were filled with a loose reticulum of connective tissue. In the pelvic regions the kidneys were composed of dense fibrous tissue which was invaded by small numbers of lymphocytes.

Occasional hepatic lobules revealed both necrosis and hemorrhage in the region of the central veins. In some, there was also central fibrosis.

A hemorrhagic fibrinopurulent exudate replaced the mucosa and infiltrated the submucosa of the colon. Here as in most of the other organs of the body the smaller arteries showed concentric intimal thickening.

\section{Case 53431}

(For details of history see (1), Case 11.) Pyelitis and toxemia in 4th pregnancy in 1929. In 1934 died of pulmonary embolism following appendectomy and uterine suspension. Before this some urinary symptoms and inconstant hypertension.

Necropsy. A dense, red, friable blood clot $10 \mathrm{~cm}$. in length occluded the right pulmonary artery. Most of this lung was hemorrhagic from early infarction. The source of the pulmonary embolus could not be determined.

The kidneys, which weighed 150 grams each, had smooth external surfaces, and were deeply congested. The mucosa of both renal pelves was thickened and had a milky appearance, but only the right pelvis and ureter were dilated.

The heart was not hypertrophied, weighing but 250 grams, and the liver was not abnormal.

Microscopic. There was extensive cloudy swelling of the renal epithelium which, however, was not necrotic. A marked vascular congestion involved both the pyramids and the glomeruli which were very large and filled their respective spaces completely. Only an occasional glomerulus was hyalinized, and there were relatively few cortical scars. The renal vessels were thickened but slightly. Most of the pelvic mucosa was desquamated; the submucosa was thickened with dense fibrous tissue free from inflammatory reaction.

\section{Case 31841}

(For details of history see (1), Case 8.) Pyelitis in 1918, aggravated by pregnancies in 1924 and 1926. After this, increasing urinary symptoms, hypertension, and renal and cardiac failure, ending fatally in 1932.

Necropsy. About 2 liters of clear, pale brown fluid were present in the peritoneal cavity, $1500 \mathrm{cc}$. in the right and $750 \mathrm{cc}$. in the left pleural cavity. The subcutaneous tissues throughout the body were water-logged. Numerous delicate fibrinous adhesions bound together epicardium and pericardium.

The right kidney weighed 50 and the left 60 grams. Both were scarred and granular externally and revealed extensive cortical scars on section. The pelves were not greatly dilated, but both were lined by thickened mucosa. The calices of the right kidney were filled with friable, black, calcareous material. The ureters were not dilated but their walls were greatly thickened. None of the larger renal vessels showed much atheromatous change. A small quantity of purulent urine filled the bladder whose mucosa was ulcerated over small areas and contained many petechial hemorrhages.

The heart was hypertrophied, weighing 425 grams 
(body weight 68 kilos), but was not dilated. There was no chronic passive congestion in the liver.

Microscopic. There was widespread scarring with mononuclear cellular infiltration throughout both kidneys. Many tubules were atrophied and others were greatly increased in size. Cellular casts in which polymorphonuclear leukocytes predominated filled many of them. The majority of the glomeruli were strikingly altered. Some were entirely replaced by hyalinized connective tissue; in others there were adhesions between tufts and capsules. Still others, and these were perhaps in the majority, revealed amorphous material like fibrin in isolated capillary loops, presenting a picture similar to that seen in so-called malignant nephrosclerosis. The afferent arterioles of such glomeruli were often greatly thickened (Figure 9) and small numbers of leukocytes were present in the glomerular spaces. Nearly all the renal arterioles had markedly hypertrophied walls, but this vascular change was seen also in the pancreas, stomach and spleen. The mucosa of the renal pelves revealed a marked round cell infiltration and a great increase of the underlying connective tissue (Figure 10). The ureters showed changes which were quite comparable to those in the pelves. In the urinary bladder the mucosa was desquamated over regions which were infiltrated with small round cells. A few fresh hemorrhages also lay scattered in the submucosa.

\section{Case 8250}

(For details of history see (1), Case 7.) Kidney trouble after first pregnancy in 1910, succeeded by recurrences and exacerbations with pregnancies in 1914, 1918, 1920, 1922 and 1924. In pregnancy in 1926 extreme hypertension, urinary frequency and burning. Persistent hypertension, albuminuria and pyuria early in 1927, death a few months later from barbital poisoning.

Necropsy. Both kidneys were small and diffusely scarred, the right weighing 57 and the left 35 grams. The capsules were thick, tough and firmly adherent to the underlying parenchyma. Each kidney had two dilated pelves and two ureters. On the right side the ureters entered the urinary bladder by two separate orifices, on the left the two ureters fused near the bladder and entered it through a single orifice. All the ureters were dilated.

Microscopic. There was a diffuse increase of connective tissue throughout both kidneys. In these scars were collected many clumps of lymphocytes and other mononuclear cells. Large numbers of renal tubules were atrophic and filled with homogeneous coagulated material. Others were dilated and lined with tall columnar cells. Most of the glomeruli were completely fibrotic, but some were increased in size and filled their spaces. Occasionally glomeruli were found which had adhesions between tufts and Bowman's capsules. The large and small renal vessels had concentrically thickened walls and greatly narrowed lumina. The renal pelves showed great congestion and edema with desquamation of the lining epithelium and granulation tissue formation along the surface. The ureters displayed the same type of inflammatory reaction.

\section{Case 47162}

(For details of history see (1), Case 9.) In 1919, at 18, scarlet fever without nephritis, but slight albuminuria and hyposthenuria. Toxemia with pregnancy in 1920. After this, increasing cardiac and renal failure with hypertension until death in 1933.

Necropsy. Together the kidneys weighed 100 grams but the right was much smaller than the left and weighed approximately 15 grams. Both were greatly scarred, the renal capsules being firmly attached to the parenchyma. The right renal artery was quite small and hypoplastic but relatively free from atheroma. The renal pelves and ureters of both kidneys were dilated to 2 or 3 times their normal size. The urinary bladder was likewise dilated and its wall was surprisingly thick. The urethra was narrow and although its lumen was patent, its wall was increased in thickness. The ureteral orifices were not obstructed.

The heart was not appreciably hypertrophied, weighing but 300 grams in a patient of 61 kilos. There was no evidence of chronic passive congestion in any of the viscera.

Microscopic. No glomeruli were present anywhere in the right kidney, which was replaced almost entirely by scar tissue in which were found dilated and atrophic tubules as well as numerous lymphocytes, large mononuclear cells and leukocytes. In the left kidney the findings were essentially similar but less intense. Many glomeruli were completely and some were partially hyalinized. There were striking vascular changes in both kidneys. These consisted of marked thickening of the walls and narrowing of the lumina of the arteries. The epithelium lining the renal pelves was in part desquamated. There were subepithelial edema, vascular congestion and leukocytic infiltration. Leukocytes were frequently found in clumps within the collecting renal tubules. The ureteral walls were thickened and infiltrated with lymphocytes. The wall of the urinary bladder was thickened; its epithelium was desquamated and the lamina propria was infiltrated with polymorphonuclear leukocytes and contained congested blood vessels. There was an increase of connective tissue in the wall of the urethra.

\section{Case $A 9526$}

(For details of history see (1), Case 6.) Pyelitis in first pregnancy in 1913. Three later pregnancies reported uncomplicated. After 1930 increasing symptoms of hypertension, renal and cardiac failure. Death in 1932.

Necropsy. There were $800 \mathrm{cc}$. of turbid, blood tinged fluid in the peritoneal cavity whose surfaces were covered with a thin film of fibrinopurulent exudate. The other serous cavities of the body were not abnormal.

Both kidneys were greatly diminished in size, the right weighing 70 and the left 80 grams. Their external surfaces were scarred and their cortical architecture was 
blurred by reason of diffuse scarring. The pelves, calices and ureters were dilated to a moderate degree and were lined by a thickened membrane.

The heart was moderately hypertrophied, weighing 360 grams, while the body weight was 54 kilos. The only other abnormalities noted macroscopically were small fresh hemorrhages in the lungs, liver and mucosa of the gastro-intestinal tract and liver.

Microscopic. Much of the architecture of the renal parenchyma was replaced by scars which were diffusely infiltrated with lymphocytes, plasma cells and moderate numbers of leukocytes. Many collecting tubules were filled with casts which were composed of granular amorphous material, cast-off epithelial cells, or polymorphonuclear leukocytes. The convoluted tubules less often contained such casts. The changes most frequently encountered in the glomeruli were fibrosis and hyalinization. Usually the whole glomerulus was thus involved. Glomerular adhesions were infrequent, nor were there conspicuous changes in Bowman's capsule. Nearly all the renal vessels had markedly narrow lumina. The narrowing was in each instance due to medial hypertrophy and increase in subintimal connective tissue. There were capillary congestion and hemorrhagic extravasations in the subepithelial layer of the renal pelves and urinary bladder. An infiltration of lymphocytes, plasma cells and other mononuclear cells was also present beneath the pelvic and cystic mucosa.

\section{Case 20067}

Born 1896. Patient was first seen in the dispensary October 29,1918, two weeks before term in her fourth pregnancy. Earlier pregnancies in 1912, 1913 and 1915 were reported to have been normal. The blood pressure was $110 / 85$ and on December 4, 98/72, the urine free from albumin on both occasions. She was delivered at home, without complications on December 24. June 2,1921 , she was seen again with incomplete abortion, but no general examination was made and she went elsewhere for treatment. In 1922 she had an abortion at 3 months for which she was treated by curettage in another hospital. In June or July 1923 another pregnancy was terminated early by self-induced abortion. November 19,1923, she appeared in the dispensary again 3 months pregnant, complaining of pain in both lower quadrants of the abdomen since the onset of pregnancy. January 2, she complained of coryza, hoarseness and palpitation; her blood pressure was 108/62, urine clear. She continued to complain of pains in the abdomen and back, but was free from objective signs until May 15, when her blood pressure was 152/90. May 26 and June 2, her ankles were swollen, but blood pressure was normal. She was delivered at home June 4 apparently without complications. November 18,1927, during another pregnancy, a diagnosis of cystitis was made, because of complaints of urinary frequency and pain and tenderness in the left lower quadrant of the abdomen, although her urine was clear and her blood pressure normal. She was delivered at home April 22 uneventfully, the urine and blood pressure remaining normal throughout. June 4, the blood pressure was 112/80. April 17, 1931, complaining of sharp pain in the right side of her neck and the right shoulder, her blood pressure was $185 / 117$, her urine contained a faint trace of albumin, the blood count was normal. Repeated examinations revealed nothing further. April 19, 1933, two months pregnant, complaining of pain in the right lower quadrant of the abdomen, palpitation, dyspnea and increasing urinary frequency, her blood pressure was $250 / 150$, heart slightly enlarged with a systolic murmur at the apex, the optic discs blurred, tortuous vessels, scars and hemorrhages in the retinae, tenderness in both lower quadrants of the abdomen, urine containing a faint trace of albumin, rare leukocytes and casts, blood nonprotein nitrogen 26 , blood count normal. She was admitted to the hospital where pregnancy was terminated by hysterotomy and the Fallopian tubes were sectioned and ligated. Symptoms and hypertension continued. March 16, 1934, her vision was failing, blood pressure $230 / 120$, blood nonprotein nitrogen 36 , phenolsulphonephthalein excretion 40 per cent. August 10, she was seized with sharp precordial pain, followed by dyspnea and palpitation. She entered the hospital acutely ill, apprehensive, with extreme dyspnea and orthopnea, obliteration of the optic discs and retinal hemorrhages, enlarged heart, coarse râles at the bases of both lungs, bilateral pleural effusion, but no subcutaneous edema. The urine contained much albumin, a few red blood cells and granular casts and moderate numbers of leukocytes; there was moderate secondary anemia, and the blood nonprotein nitrogen was $84 \mathrm{mgm}$. per cent. She did not respond to treatment and died August 22, with a terminal blood nonprotein nitrogen of $172 \mathrm{mgm}$. per cent.

Necropsy. About $400 \mathrm{cc}$. of clear, yellow fluid were present in each pleural cavity, but the other serous cavities did not contain an excess of fluid.

The right kidney weighed 140 and the left 145 grams. Their external surfaces were coarsely granular and their cortices were quite narrow. Both externally and on section there could be seen small fresh hemorrhages in the cortex. The renal pelves and ureters were not dilated or otherwise altered. The larger renal vessels did not appear to be thickened.

The heart was distinctly hypertrophied and weighed 495 grams (body weight 62 kilos). Its ventricles were dilated and there was evidence of chronic passive congestion in the liver and lungs.

Microscopic. In both renal cortex and medulla were numerous small scars infiltrated with small numbers of lymphocytes. The convoluted tubules showed cloudy swelling of their epithelium and often containued coagulated material in their lumina. The glomeruli presented a great variety of changes consisting of partial and complete fibrosis and hyalinization, adhesions between tufts and capsules, vascular congestion, and hemorrhage into glomerular spaces. In rare instances the epithelium of Bowman's capsule had proliferated to form crescents. A striking glomerular change was the thickening of the subendothelial connective tissue and the 
presence of a fibrin-like material in the capillary tufts. The afferent glomerular arterioles were strikingly thickened with slit-like lumina and walls which seemed to be hyalinized. Similar changes were noted in the larger arterioles. The large renal arteries were relatively normal. There was no sign of an inflammatory reaction in the renal pelves.

\section{Case 43495}

Born 1898. Patient was first seen in the prenatal clinic, May 27, 1926, three months pregnant, with blood pressure 150/90. Pregnancies in 1921 and 1922 were reported uncomplicated, but in the third, in 1924, her blood pressure is said to have been high. On all subsequent visits until the end of pregnancy blood pressure and urine were found normal, and she was delivered in the hospital January 13, 1927, without difficulty. Blood pressures in May, 1927, were normal, March 11, 1929, she again came to the prenatal clinic, 4 months pregnant. August 26, the blood pressure which had been consistently normal, was $142 / 82$, the urine loaded with albumin. August 28, she was admitted at term, blood pressure $156 / 100$, eyegrounds normal, albuminuria profuse, no edema, blood nonprotein nitrogen $24 \mathrm{mgm}$. per cent. She was delivered August 30 and had an uneventful puerperium. October 7 , in the dispensary, her blood pressure was $160 / 108$; she complained only of pain and tenderness in the sacro-iliac region. Subsequent blood pressures: October 15, 130/80; November 19, $152 / 100$; December 16,130/100. The urine was normal February 4 and 7, 1930. March 17, she entered the hospital for dilatation and curettage, following an abortion in the third month, with blood pressure 150/90. November 6, it was $165 / 100$, and September 18, 1931, $150 / 90$. On this last occasion she complained of headache and blurred vision. May 28, 1932, when she entered the hospital for a perineal repair the blood pressure was $160 / 108$, the heart slightly enlarged, urine containing moderate amounts of albumin and occasional leukocytes. Subsequent blood pressures, after operation, were $130 / 80$, $135 / 90$ and $132 / 92$. June 24 , in the dispensary, the blood pressure was $160 / 110$, the urine clear. Early in September she began to suffer increasingly from headaches. After breakfast on September 17, she vomited, a little later she developed a severe headache, and about 2:00 p.m. had a convulsion, succeeded by stupor. She was brought to the hospital, with temperature $102.8^{\circ}$, pulse 72 , blood pressure $150 / 98$, comatose, vomiting, petechiae over the left forearm, stiff neck, blurring of the margins of the optic discs, heart moderately enlarged, occasional premature beats, no murmurs. The spinal fluid was bloody, and under increased pressure. After desensitization she was given intraspinally antimeningococcus serum, which produced accelerated serum sickness. She continued comatose until death, September 23. The temperature by September 20 had risen to $106.4^{\circ}$, blood nonprotein nitrogen was $42 \mathrm{mgm}$. per cent. The blood count was normal except for a leukocytosis $(18,500$ to 15,500 with 96 to 77 per cent polynuclears). The urine contained a slight quantity of albumin, occasional red blood cells and granular casts, specific gravity up to 1.026 . The blood pressure was 150 to $178 / 85$ to 100 until the last day, when it fell to $110 / 86$.

Necropsy. The right kidney weighed 125 , the left 150 grams. The external surfaces of both were smooth and there were no scars in the cortex of either. The major renal vessels appeared to be free of atheroma. There was no evidence of pelvic or ureteral dilatation and infection.

A small hemorrhagic infarct was seen in the lower pole of the left kidney and several similar lesions of small size were noted in the spleen. Massive hemorrhages and tissue necrosis were found in both frontal lobes of the brain, which was the site of an intraventricular and subarachnoid hemorrhage.

The heart was not hypertrophied and weighed but 325 grams, whereas the body weight was 81 kilos. There was no evidence of passive congestion in the viscera.

Microscopic. Except for cloudy swelling the epithelium of the renal tubules was intact, and the lumina contained no casts. There were few scars in the cortex and pyramids and only an occasional glomerulus was completely hyalinized. On the other hand, in numerous glomeruli could be seen some degree, slight to moderate, of fibrin deposition in capillary tufts and thickening of afferent arterioles. Medial thickening was also noted in many of the larger renal vessels, but never to a very marked extent. The pelvic mucosa was not altered in appearance and the submucosa was free of cellular exudate.

\section{Case 58750}

Born 1894. Patient was first seen in the prenatal clinic January 25, 1927, three months pregnant, with blood pressure $170 / 110$ and minimal albuminuria. She reported that her first pregnancy, in 1926, had terminated spontaneously in stillbirth at 7 months, after a period of vomiting, kidney trouble and edema of the legs. She was brought into the hospital, but refused treatment. The 1927 pregnancy and another in 1929 terminated, like the first, in spontaneous abortions at 7 months. The toxemic symptoms, however, became more severe with each pregnancy. After the last, she remained reasonably well until December 1931, when she began to suffer increasingly from dyspnea on exertion and orthopnea. About Christmas, edema began in the ankles and gradually spread to involve the legs, thighs and trunk. About the middle of January 1932, her right leg became infected and at about the same time her vision began to deteriorate. January 30 or 31 , she became delirious. She entered the hospital, February 2, restless, disoriented, with marked dyspnea and orthopnea, temperature $99^{\circ}$, pulse 90 , blood pressure $228 / 134$, advanced retinal sclerosis, tongue and throat dry, raw and coated with yellow exudate, signs of pleural effusions and râles at the bases of both lungs with wheezes and rhonchi above, heart and liver greatly enlarged, massive edema of the lower extremities and trunk, ulcerations on both shins and cellulitis of the right leg, slight anemia, high leukocytosis 
(24,700 with 92 per cent polynuclears), urine containing a little albumin and occasional leukocytes, blood nonprotein nitrogen $64 \mathrm{mgm}$. per cent, serum protein 6.32 per cent, with albumin 3.27. She did not improve under treatment and died February 4. The temperature never exceeded $100.4^{\circ}$.

Necropsy. There was marked subcutaneous edema of both lower extremities, and in the right leg, in addition, multiple superficial ulcers from which exuded purulent material. About $100 \mathrm{cc}$. of thin, clear fluid were present in the peritoneal cavity, $300 \mathrm{cc}$. in the left and 1075 cc. in the right thoracic cavity, which also contained fibrin. The liver and both lungs showed evidence of marked chronic passive congestion.

The left kidney weighed 125 and the right 175 grams. Their external surfaces were finely granular and their cortices diffusely scarred. There was no apparent dilatation of the calices, pelves and ureters. The renal arteries were not appreciably thickened.

There was rather marked hypertrophy and dilatation of the heart which weighed 625 grams (body weight 83 kilos). The valves were normal.

Microscopic. There were numerous small scars in the renal cortex. Many tubules were small and atrophic but others were greatly dilated. The epithelium of the latter was frequently swollen and granular. In some of the tubules the epithelium was necrotic and desquamated; it often lay mingled with polymorphonuclear leukocytes in the lumina of the collecting tube. Completely hyalinized glomeruli were present as well as some which were atrophied and reduced to a few capillary loops. Many glomeruli were hypertrophied and filled their spaces completely. Very often glomeruli were seen whose capillary loops were replaced with a pink-staining material like fibrin, the glomerular spaces containing small numbers of leukocytes, the walls of the afferent arterioles greatly thickened and the lumina partially or completely occluded (Figure 11). These changes resembled in every way those seen in so-called malignant nephrosclerosis. Other small arterioles in addition to the vasa afferentia had concentrically thickened walls with greatly narrowed or completely occluded lumina (Figure 12). Similar changes were seen throughout the body.

\section{BIBLIOGRAPHY}

1. Peters, J. P., Lavietes, P. H., and Zimmerman, H. M., Pyelitis in toxemias of pregnancy. Am. J. Obst. and Gynec., 1936, 32, 911.

2. Volhard, F., and Fahr, T., Die Brightsche Nierenkrankheit. Die doppelseitigen hämatogenen Nierenkrankheiten. Berlin, 1914. Volhard, F., 1918.

3. Bell, E. T., Renal lesions in the toxemias of pregnancy. Am. J. Path., 1932, 8, 1.

4. Herrick, W. W., and Tillman, A. J. B., Toxemia of pregnancy. Its relation to cardiovascular and renal disease; clinical and necropsy observations with a long follow-up. Arch. Int. Med., 1935, 55, 643.

5. Mussey, R. D., and Keith, N. M., Significance of nephritis of pregnancy. J. A. M. A., 1928, 91, 2044.

Rockwood, R., Mussey, R. D., and Keith, N. M., A clinical study of nephritis in cases of pregnancy. Surg., Gynec. and Obst., 1926, 42, 342. 